\title{
Supramolecular Reinforcement of a Large Pore 2D Covalent Organic Framework
}

Shashini D. Diwakara, Whitney S. Y. Ong, Yalini H. Wijesundara, Robert L. Gearhart, Fabian C. Herbert, Sarah G. Fisher, Gregory T. McCandless, Sampath B. Alahakoon, Jeremiah J. Gassensmith, Sheel C. Dodani, Ronald A. Smaldone*

The Department of Chemistry and Biochemistry, The University of Texas at Dallas, Richardson, Texas, 75080, United States.

*email: ronald.smaldone@utdallas.edu

ABSTRACT: Two dimensional covalent organic frameworks (2D-COFs) are a class of crystalline porous organic polymers that consist of covalently linked, two dimensional sheets that can stack together through non-covalent interactions. Here we report the synthesis of a novel COF, called PyCOFamide, which has an experimentally observed pore size that is greater than $6 \mathrm{~nm}$ in diameter. This is among the largest pore size reported to date for a 2D-COF. PyCOFamide exhibits permanent porosity and high crystallinity as evidenced by the nitrogen ad-

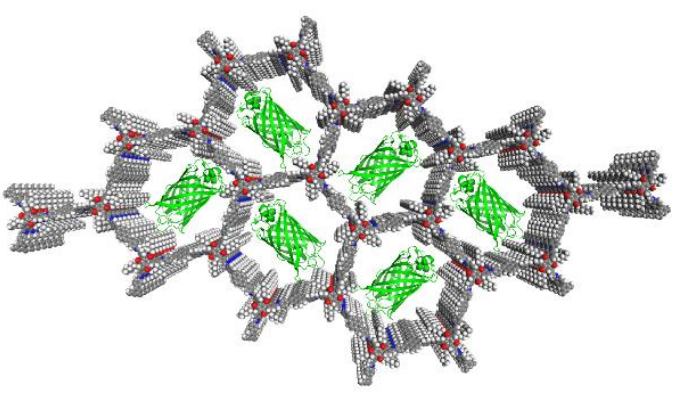
sorption, powder X-ray diffraction, and high-resolution transmission electron microscopy. We show that the pore size of PyCOFamide is large enough to accommodate fluorescent proteins such as Superfolder green fluorescent protein and $\mathrm{mNeonGreen.} \mathrm{This} \mathrm{work} \mathrm{demonstrates} \mathrm{the} \mathrm{utility} \mathrm{of} \mathrm{non-covalent} \mathrm{structural}$ reinforcement in 2D-COFs to produce larger, persistent pore sizes than previously possible.

Two-dimensional covalent organic frameworks (2D-COFs) are crystalline, porous, organic polymer networks built from organic monomers and linked together by dynamic covalent bonds. ${ }^{1-3}$ Researchers have explored the landscape of COF structures for use in applications such as molecular separation, ${ }^{4,5}$ sensing ${ }^{6,7}$ gas storage, ${ }^{8,9}$ electronic devices, ${ }^{10,11}$ and catalysis. ${ }^{12,13}$ COFs can be designed for various applications by modifying their crystallinity, pore size, and surface area from the bottom up. ${ }^{3,14-16}$

One fundamental challenge in porous materials design involves the synthesis of structures with large, and persistent pores. There are several general obstacles in this pursuit, including the solubility of large organic molecules needed to generate the large pore sizes, ${ }^{17,18}$ as well as the propensity for pore collapse or structural damage upon solvent removal. ${ }^{19-23}$ As a result, 2D-COFs with a pore diameter larger than 5 $\mathrm{nm}$ are not common. ${ }^{14,24-26}$ There are additional challenges in the design of large pore 2D-COFs as they use more flexible organic linkages ${ }^{27-30}$ in the covalent sheets in comparison with more rigid metal-organic frameworks (MOFs), ${ }^{17}$ along with the potential for inefficient stacking of the 2D layers in an eclipsed orientation ${ }^{31,32}$ These 2D sheets are held together by non-covalent interactions such as donoracceptor complexes, ${ }^{15}$ aromatic stacking interactions, ${ }^{15,33,34}$ dipole-dipole interactions, ${ }^{35,36}$ van der Waals forces, ${ }^{37}$ and hydrogen bonding. ${ }^{38-43}$

A number of general methods to improve the crystallinity and surface area of 2D-COFs have been extensively studied. ${ }^{15,33,44,45}$ COF activation methods have evolved significantly to include the use of fluorous liquids ${ }^{27}$ or supercritical carbon dioxide $\left(\mathrm{scCO}_{2}\right)^{28-30}$ to remove the organic solvents used during the polymerization. This strategy is beneficial as it can be used on any material and does not require any synthetic modification of the COF structure. However, more recent work has shown that by designing non-covalent interactions that are directed specifically between the layers, COFs with significantly improved crystallinity and surface area can be attained, even without $\mathrm{scCO}_{2}$ activation. ${ }^{15,26,43,45}$ However, as pore sizes increase, even the gentlest solvent activation methods can cause damage to the structure. In these situations, the only way to preserve these large pores may be through a combination of structural reinforcement and improved activation methods. 


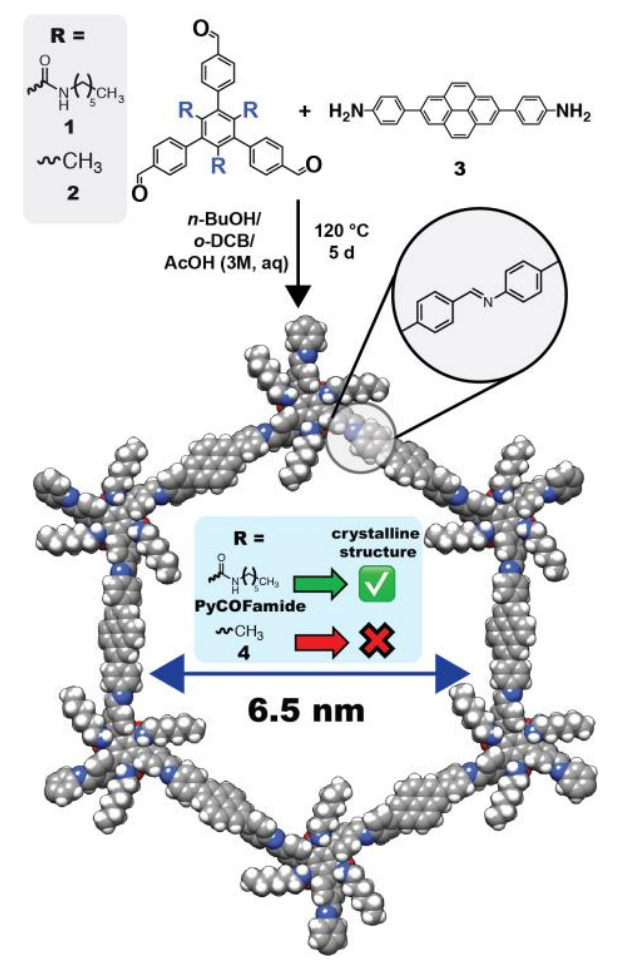

Figure 1. Synthesis and structure of PyCOFamide.

Our group recently reported a class of 2D-COFs with secondary amide sidechains that can facilitate interlayer hydrogen bonding (COFamide 1-2) ${ }^{43}$ Given our previous observation that the highly correlated interlayer hydrogen bonding of the COFamide series made them resistant to pore collapse using conventional solvent activation conditions, we aimed to expand the pore size significantly with the expectation that the rigidified layer structure would be able to support larger pores. In this study, we polymerized a tritopic aldehyde with amide sidechains (1) and a ditopic amine linker 4,4'-(pyrene-2,7-diyl)dianiline (3) to produce an imine-linked COF called PyCOFamide (Figure 1). A control polymer without amide groups was also synthesized (4) using a monomer with methyl groups in place of the secondary amide groups (2) in order to investigate the importance of the interlayer hydrogen bonding on the COF structure.

Polymerization reactions were carried out in a solvent mixture of $o$-dichlorobenzene, $n$-butanol and acetic acid (3M, aq) in a ratio of 1.9:1:0.1 at $120^{\circ} \mathrm{C}$ for $5 \mathrm{~d}$ to produce PyCOFamide, or polymer 4 . The insoluble polymers obtained were activated using $\mathrm{scCO}_{2}$ before further characterization. The PyCOFamide was obtained as an ash-colored powder whereas polymer 4 was a light-yellow powder. These powders are insoluble in common organic solvents such as acetone, methanol, dichloromethane, and hexane.

The FT-IR spectrum of PyCOFamide (Figure 2A) showed the appearance of a signal at $1628 \mathrm{~cm}^{-1}$, which is characteristic of an imine stretching vibration. The disappearance of the aldehyde $\mathrm{C}=0$ stretching modes at $1697 \mathrm{~cm}^{-1}$ and amine $\mathrm{N}-\mathrm{H}$ vibrations at $3464 \mathrm{~cm}^{-1}$ confirm the absence of starting monomers in the final polymer. Additionally, the amide N-H stretching vibrations of PyCOFamide shift to $3309 \mathrm{~cm}^{-1}$ compared to the amide $\mathrm{N}-\mathrm{H}$ stretching modes of 1 at $3278 \mathrm{~cm}^{-1}$. This shift can be attributed to the formation of interlayer hydrogen bonding interactions. ${ }^{43}$ We digested PyCOFamide in acidic DMSO- $d_{6}$ to determine the monomer incorporation ratio. We found the aldehyde to amine monomer ratio to be 1:1.5 which is consistent with the initial feed ratio (Figure S8).

Powder X-ray diffraction (PXRD) experiments were performed to determine the crystallinity of the synthesized polymers. Sharp diffraction peaks were observed in the $\mathrm{scCO}_{2}$ activated PyCOFamide. An intense, and narrow diffraction peak corresponding to the (100) crystal plane was observed at $3.1^{\circ} 2 \theta$ in the PyCOFamide diffraction pattern (Figure 2B). In addition to the peak at $3.1^{\circ}$, other peaks were observed at $4.8,6.2,7.8,9.4,10.9$ and $18.5^{\circ}$ which can be attributed to the diffraction from the (110), (200), 

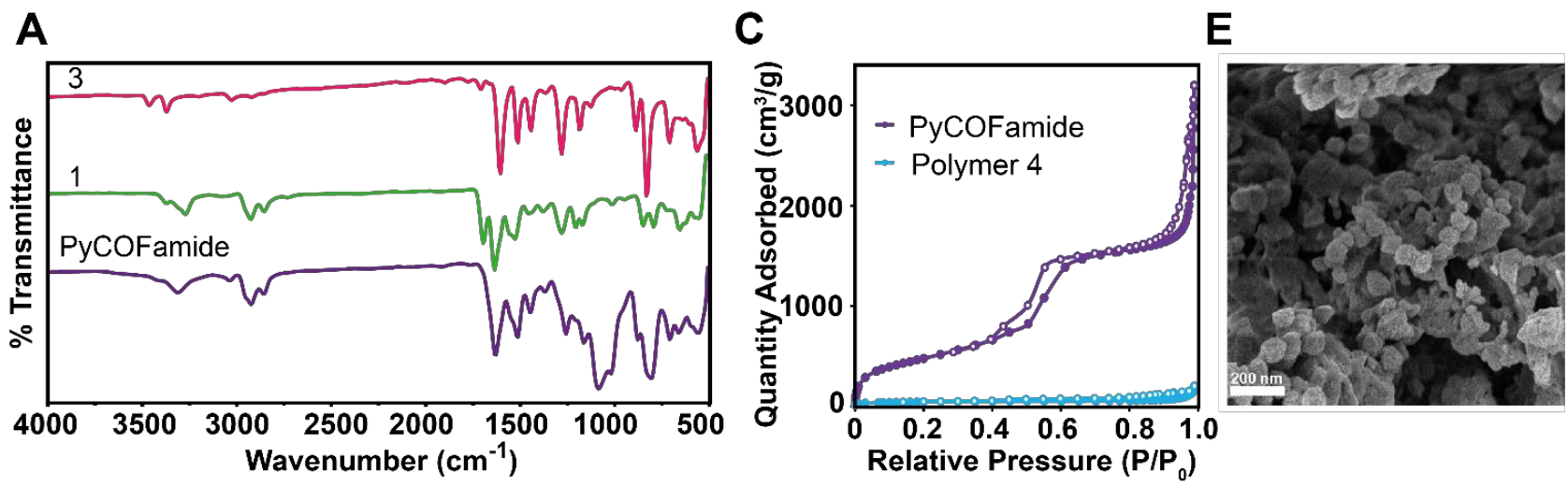

B

D
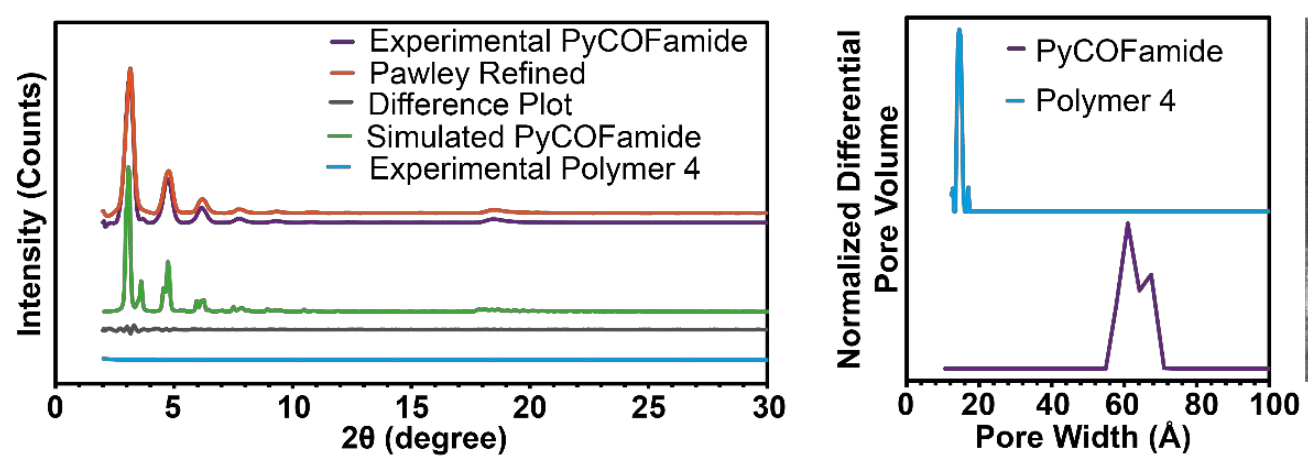

$F$

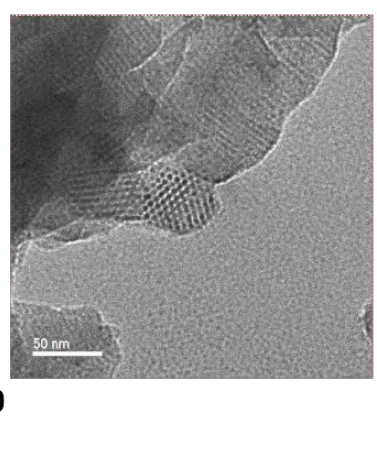

Figure 2. (A) FT-IR spectra of PyCOFamide and starting monomers. (B) PXRD patterns of PyCOFamide (purple), Pawley refined (red), the simulated PyCOFamide pattern (green), difference plot (black) and polymer 4 (blue). (C) Nitrogen adsorption (closed circles) and desorption (open circles) isotherm for PyCOFamide (purple) and polymer 4 (blue). (D) Pore size distributions for PyCOFamide and control polymer 4. (E) SEM of PyCOFamide. (F) HR-TEM of PyCOFamide.

(210), (120), (220), and (001) crystal planes. Molecular modeling and Pawley refinement of the diffraction pattern was performed using the BIOVIA Materials Studio software package. The initial PyCOFamide lattice structure was built in the $\mathrm{P} 6 / \mathrm{m}$ space group and energy minimized in $\mathrm{P} 1$ using the universal force field (UFF). The experimental PXRD patterns of PyCOFamide are well-matched with the simulated PXRD patterns obtained by modeling an eclipsed stacking arrangement (Figure S6). The (001) reflection for PyCOFamide appears at $18.5^{\circ}$, which is characteristic for COFamides as they have larger interlayer spacing distances owing to the steric hindrance caused by the out of plane phenyl rings and amide groups at the node positions.$^{43}$ Additionally, the interlayer distance predicted from the simulated crystal structure of $\sim 5.1 \AA$, is similar to the experimental value $(\sim 4.8 \AA)$ obtained from PXRD. No peaks were observed in the PXRD pattern of polymer 4 (Figure 2B) indicating that it is amorphous in nature.

The Brunauer-Emmett-Teller (BET) surface area and pore size distributions of PyCOFamide and $\mathbf{4}$ were measured by nitrogen adsorption measurements at $77 \mathrm{~K}$ (Figure $2 \mathrm{C}$ ). When activated using $\mathrm{scCO}_{2} \mathrm{PyCO}_{\mathrm{CO}}$ Famide has a BET surface area of $1682 \mathrm{~m}^{2} / \mathrm{g}$. However, when it is subjected to conventional activation (washing with organic solvents and heating under dynamic vacuum), the BET surface area is significantly lower $\left(8 \mathrm{~m}^{2} / \mathrm{g}\right)$ (Figure S5). Pore collapse or decrystallization is common when using conventional solvent activation because of the capillary effect that occurs during solvent evaporation under vacuum. ${ }^{30}$ In comparison, the control polymer 4 has a low accessible surface area $\left(169 \mathrm{~m}^{2} / \mathrm{g}\right)$ and no observable crystallinity by PXRD regardless of activation method, indicating that the hydrogen bonding interactions are key to reinforcing the eclipsed stacking of the material. Nitrogen adsorption isotherm profiles of PyCOFamide have a type-IV isotherm shape, which is characteristic of mesoporous materials (pores $>20$ 
$\AA$ ). The pore size distribution and total pore volume were determined using the non-local density functional theory (NLDFT), cylindrical pores-oxide surface model. PyCOFamide has a narrow pore size distribution centered at 61 and $67 \AA$ (Figure 2D) that agrees with the calculated pore size (65 $\AA$ ) from the computational model with eclipsed stacking (Figure S6).

Scanning electron microscopy (SEM) images of the PyCOFamide powder reveal that it has discotic morphology (Figure 2E) with aggregated discs of about $70 \mathrm{~nm}$ in size. The highly ordered, periodic structure of PyCOFamide could be observed in the high-resolution transmission electron microscope (HR-TEM) image (Figure 2F). This image clearly shows the hexagonal pore arrangement indicating long-range order and the layered arrangement of PyCOFamide. These observations are consistent with the PXRD data. The size of the hexagonal pores is also in agreement with those obtained from the nitrogen adsorption isotherm.

To test the stability of PyCOFamide, the COF was immersed in various aqueous solutions and organic solvents such as $N, N$-dimethylformamide (DMF), dimethyl sulfoxide (DMSO), 1,4-dioxane, $N$-methyl-2pyrrolidone (NMP), sulfuric acid ( $1 \mathrm{M}$, aq), sodium hydroxide $(1 \mathrm{M}, \mathrm{aq})$ and phosphate buffered saline (PBS, $\mathrm{pH}=7.4$ ). The retention of crystallinity after immersion of $3 \mathrm{~d}$ was studied by PXRD (Figure S7). The results revealed that the crystallinity of PyCOFamide is retained in DMF, and sodium hydroxide and PBS. However, the crystallinity of PyCOFamide is damaged in the sulfuric acid, which may be due to hydrolysis of the imine linkages under acidic conditions. Additionally, PyCOFamide crystallinity was lost in 1,4-dioxane, DMSO, and NMP solvents likely due to their polarity that could contribute to the exfoliation or the displacement of COF layers. Interestingly, the characteristic peak around $18.5^{\circ}$ corresponding to the interlayer stacking distance in COFamide-based materials remains visible in the PXRD patterns even after the other peaks have disappeared. We hypothesize that this could arise from continued interlayer stacking between disordered sheets after decrystallization.

A

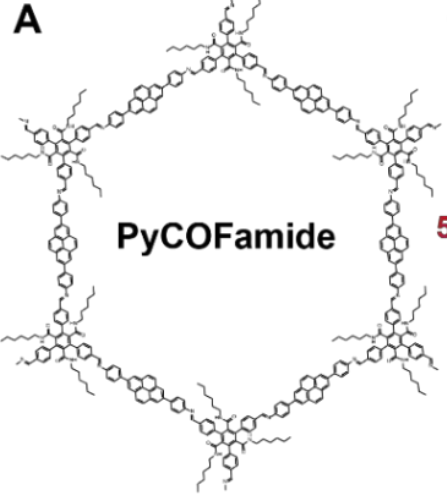

B

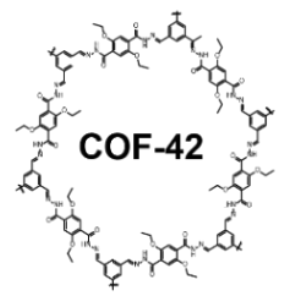

C
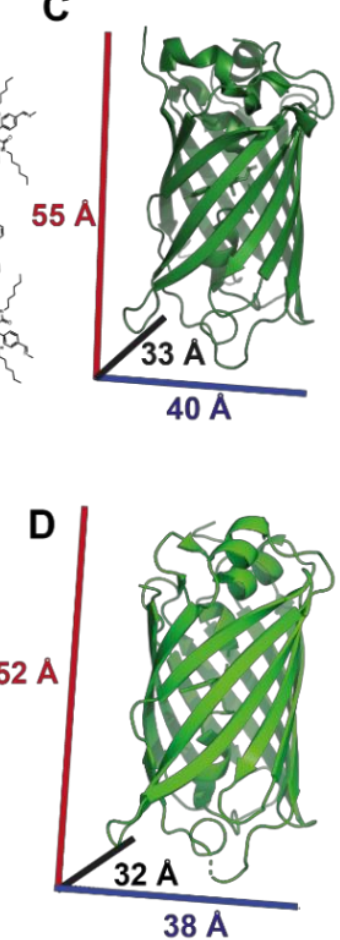
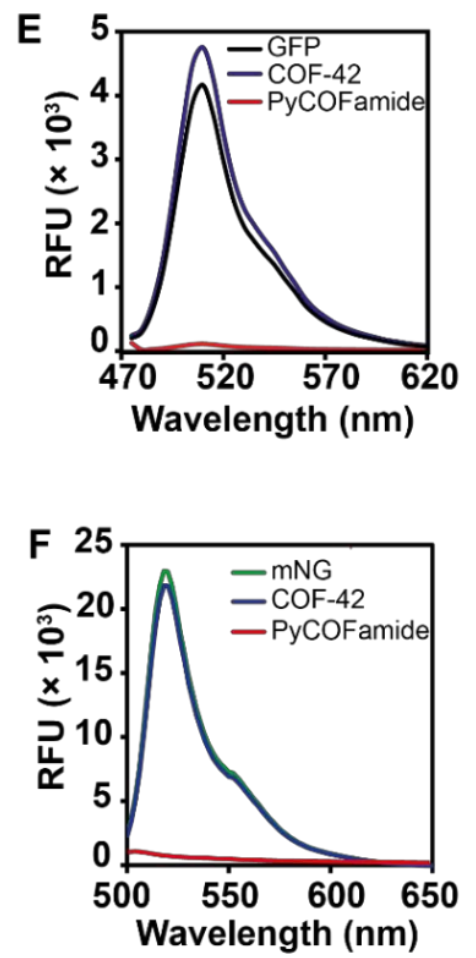

G

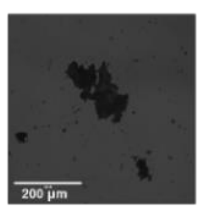

H
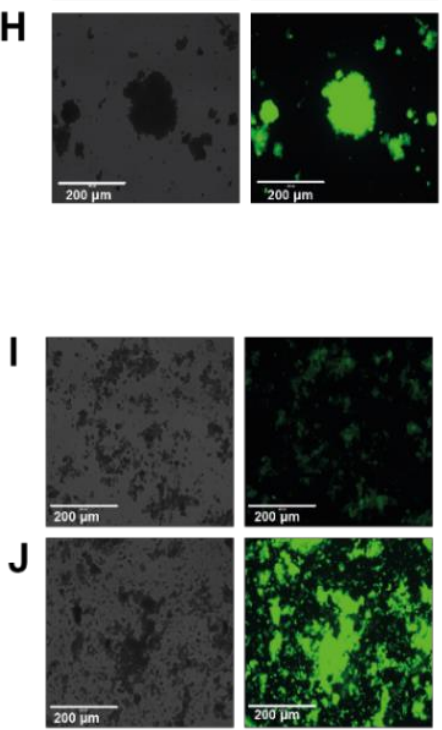

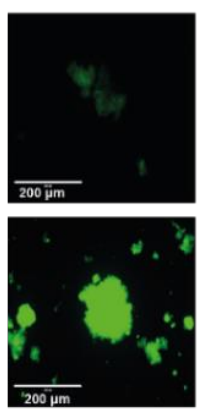

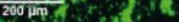

Figure 3. (A) Structure of PyCOFamide. (B) Structure of COF-42. (C) Dimensions of sfGFP (PDB ID: 2B3P) and (D) mNG (PDB ID: 5LTR). Fluorescence spectra of (E) sfGFP loading into PyCOFamide and COF-42. Fluorescence spectra of $(\mathrm{F}) \mathrm{mNG}$ loading into PyCOFamide and COF-42. Fluorescence microscopy images of (G) sfGFP loaded COF-42 pellet (H) sfGFP loaded PyCOFamide pellet (I) mNG loaded COF-42 pellet and (J) $\mathrm{mNG}$ loaded PyCOFamide pellet. 
The large pore size of PyCOFamide (Figure 3A), combined with its stability in aqueous solutions like PBS encouraged us to study its ability to host proteins. Porous materials, including MOFs, ${ }^{17,46-48} \mathrm{COFs}^{49-52}$ mesoporous silica, ${ }^{53,54}$ hydrogen-bonded organic frameworks (HOF), ${ }^{55}$ zeolites, $^{56}$ and cage compounds ${ }^{57}$ have been used to adsorb a variety of biomolecules as guests into their pores. Once inside the pores of a polymer, the reactive properties or stability can be greatly affected. However, the inclusion of biomolecules into the individual pores of COFs is less common because the pore sizes of 2D-COFs are often too small to host an entire protein. As a proof-of concept, we selected two $\beta$-barrel fluorescent proteins, Superfolder green fluorescent protein (sfGFP) $(\mathrm{MW}=26.8 \mathrm{kDa})^{58,59}$ (Figure 3C) and mNeonGreen (mNG) $(\mathrm{MW}=26.6 \mathrm{kDa})^{60}$ (Figure 3D). These proteins were selected as their approximate dimensions would allow for encapsulation within PyCOFamide, and the infiltration of protein into the COF pores can be easily monitored using fluorescence spectroscopy and fluorescence microscopic imaging. $\mathrm{scCO}_{2}$ activated samples were used in this experiment. COF-42 (Figure 3B), ${ }^{61}$ which has a smaller pore diameter $(2.3 \mathrm{~nm})$ than PyCOFamide was used as a control since both sfGFP and $\mathrm{mNG}$ are too big to fit into its pores. We prepared samples with different COF to protein ratios and monitored the fluorescence signal of both sfGFP $(509 \mathrm{~nm})$ and $\mathrm{mNG}(520 \mathrm{~nm})$ in solutions before and after PyCOFamide or COF-42 were added to them. In the ratio of COF to protein at 9:1, where the concentration of COF is $0.9 \mathrm{mg} / \mathrm{mL}$ and the concentration of sfGFP and $\mathrm{mNG}$ are 0.16 and $0.1 \mathrm{mg} / \mathrm{mL}$ respectively, we observed that the fluorescence of the supernatant of both proteins drastically decreased when PyCOFamide was added, whereas the control solutions containing COF-42 do not (Figure 3E) and (Figure 3F). This indicates that both $\mathrm{mNG}$ and sfGFP are being drawn out of solution and into the pores of PyCOFamide.

We further confirmed the inclusion of protein in the pores of PyCOFamide by using fluorescence microscopy to directly observe the change in fluorescence of the solid COF materials before and after addition of sfGFP or mNG. Some fluorescence is observable in COF-42 samples (Figure 3G) and (Figure 3I) which is likely attributed to surface adsorption of the proteins on the COF material. In contrast, PyCOFamide particle are highly fluorescent indicating a greater extent of protein inclusion (Figure $3 \mathrm{H}$ and $\mathrm{J}$ ). The retention of fluorescence for sfGFP and mNG in PyCOFamide also indicates that the proteins are not denatured and retain their structure after adsorption within the COF.

In conclusion, we have designed and synthesized a novel large pore COF whose structure is stabilized through interlayer hydrogen bonding. PyCOFamide exhibits large pore channels of $>6 \mathrm{~nm}$ in diameter, which is among the largest reported to date in a 2D-COF. The interlayer hydrogen bonding interactions in this COF are key to its ability to maintain its structure after activation, as similar monomers incapable of hydrogen bonding do not produce ordered COFs. The design strategies for making large pore 2D-COFs in the future will necessitate new design approaches that consider both mild activation techniques (e.g., $\mathrm{scCO}_{2}$ ) and the supramolecular interactions between the layers. ${ }^{3,24,26,36,45}$ We have also demonstrated that large biomolecules such as fluorescent proteins can be loaded into the pores of PyCOFamide without loss of their function, suggesting that these COFs could potentially be used in the future as hosts for enzymes or biosensing proteins. Taken together, our study sets the stage for expanding the scope of COF chemistry providing a supramolecular design strategy to synthesize COFs with large, persistent pores.

\section{ACKNOWLEDGMENTS}

R.A.S. acknowledges support from the Army Research Laboratory (W911NF-18-2-0035). S.C.D acknowledges from UT Dallas, the Welch Foundation (AT-2060-20210327), and the National Institute of General Medical Sciences of the National Institutes of Health (R35GM128923). J.J.G. acknowledges Robert A. Welch Foundation (Grant AT-1989-20190330) for funding this research and the NSF (Grants CAREER award DMR-1654405 and DMR-2003534) for funding the integration of his entire scholarly and educational activities. This work is the sole responsibility of the authors and does not represent the views of the funding sources. 


\section{REFERENCES}

(1) Côté, A. P.; Benin, A. I.; Ockwig, N. W.; Keeffe, M.; Matzger, A. J.; Yaghi, O. M. Porous, Crystalline, Covalent Organic Frameworks. Science 2005, 310, $1166-1170$.

(2) Geng, K.; He, T.; Liu, R.; Dalapati, S.; Tan, K. T.; Li, Z.; Tao, S.; Gong, Y.; Jiang, Q.; Jiang, D. Covalent Organic Frameworks: Design, Synthesis, and Functions. Chem. Rev. 2020, 120, 8814-8933.

(3) Alahakoon, S. B.; Diwakara, S. D.; Thompson, C. M.; Smaldone, R. A. Supramolecular Design in 2D Covalent Organic Frameworks. Chem. Soc. Rev. 2020, 49, 1344-1356.

(4) Lohse, M. S.; Stassin, T.; Naudin, G.; Wuttke, S.; Ameloot, R.; de Vos, D.; Medina, D. D.; Bein, T. Sequential Pore Wall Modification in a Covalent Organic Framework for Application in Lactic Acid Adsorption. Chem. Mater. 2016, 28, 626-631.

(5) Kandambeth, S.; Biswal, B. P.; Chaudhari, H. D.; Rout, K. C.; Kunjattu H., S.; Mitra, S.; Karak, S.; Das, A.; Mukherjee, R.; Kharul, U. K.; Banerjee, R. Selective Molecular Sieving in Self-Standing Porous Covalent-Organic-Framework Membranes. Adv. Mater. 2017, 29, 1603945.

(6) Ascherl, L.; Evans, E. W.; Hennemann, M.; di Nuzzo, D.; Hufnagel, A. G.; Beetz, M.; Friend, R. H.; Clark, T.; Bein, T.; Auras, F. Solvatochromic Covalent Organic Frameworks. Nat. Commun. 2018, 9, 3802.

(7) Jhulki, S.; Evans, A. M.; Hao, X.-L.; Cooper, M. W.; Feriante, C. H.; Leisen, J.; Li, H.; Lam, D.; Hersam, M. C.; Barlow, S.; Brédas, J.-L.; Dichtel, W. R.; Marder, S. R. Humidity Sensing through Reversible Isomerization of a Covalent Organic Framework. J. Am. Chem. Soc. 2020, 142, 783-791.

(8) Furukawa, H.; Yaghi, O. M. Storage of Hydrogen, Methane, and Carbon Dioxide in Highly Porous Covalent Organic Frameworks for Clean Energy Applications. J. Am. Chem. Soc. 2009, 131, 88758883.

(9) Ma, H.; Ren, H.; Meng, S.; Yan, Z.; Zhao, H.; Sun, F.; Zhu, G. A 3D Microporous Covalent Organic Framework with Exceedingly High $\mathrm{C}_{3} \mathrm{H}_{8} / \mathrm{CH}_{4}$ and $\mathrm{C}_{2}$ Hydrocarbon/ $\mathrm{CH}_{4}$ Selectivity. Chem. Commun. 2013, 49, 9773-9775.

(10) Samanta, P.; Desai, A. v; Anothumakkool, B.; Shirolkar, M. M.; Karmakar, A.; Kurungot, S.; Ghosh, S. K. Enhanced Proton Conduction by Post-Synthetic Covalent Modification in a Porous Covalent Framework. J. Mater. Chem. 2017, 5, 13659-13664.

(11) Wang, M.; Wang, M.; Lin, H.-H.; Ballabio, M.; Zhong, H.; Bonn, M.; Zhou, S.; Heine, T.; Cánovas, E.; Dong, R.; Feng, X. High-Mobility Semiconducting Two-Dimensional Conjugated Covalent Organic Frameworks with p-Type Doping. J. Am. Chem. Soc. 2020, 142, 21622-21627.

(12) Xu, H.; Chen, X.; Gao, J.; Lin, J.; Addicoat, M.; Irle, S.; Jiang, D. Catalytic Covalent Organic Frameworks via Pore Surface Engineering. Chem. Commun. 2014, 50, 1292-1294.

(13) Song, L.; S., D. C.; Yue-Biao, Z.; Nikolay, K.; M., N. E.; Yingbo, Z.; R., P. A.; Dohyung, K.; Peidong, Y.; M., Y. O.; J., C. C. Covalent Organic Frameworks Comprising Cobalt Porphyrins for Catalytic $\mathrm{CO}_{2}$ Reduction in Water. Science 2015, 349, 1208-1213.

(14) Li, Z.; He, T.; Gong, Y.; Jiang, D. Covalent Organic Frameworks: Pore Design and Interface Engineering. Acc. Chem. Res. 2020, 53, 1672-1685.

(15) Chen, X.; Addicoat, M.; Irle, S.; Nagai, A.; Jiang, D. Control of Crystallinity and Porosity of Covalent Organic Frameworks by Managing Interlayer Interactions Based on Self-Complementary $\pi$-Electronic Force. J. Am. Chem. Soc. 2013, 135, 546-549.

(16) Huang, N.; Wang, P.; Jiang, D. Covalent Organic Frameworks: A Materials Platform for Structural and Functional Designs. Nat. Rev. Mater. 2016, 1, 16068.

(17) Hexiang, D.; Sergio, G.; E., C. K.; Cory, V.; Hiroyasu, F.; Mohamad, H.; Felipe, G.; C., W. A.; Zheng, L.; Shunsuke, A.; Hiroyoshi, K.; Michael, O.; Osamu, T.; Fraser, S. J.; M., Y. O. Large-Pore Apertures in a Series of Metal-Organic Frameworks. Science 2012, 336, 1018-1023.

(18) Banglin, C.; M., E.; T., H. S.; M., O.; M., Y. O. Interwoven Metal-Organic Framework on a Periodic Minimal Surface with Extra-Large Pores. Science 2001, 291, 1021-1023.

(19) Farha, O. K.; Hupp, J. T. Rational Design, Synthesis, Purification, and Activation of Metal-Organic Framework Materials. Acc. Chem. Res. 2010, 43, 1166-1175. 
(20) Nelson, A. P.; Farha, O. K.; Mulfort, K. L.; Hupp, J. T. Supercritical Processing as a Route to High Internal Surface Areas and Permanent Microporosity in Metal-Organic Framework Materials. J. Am. Chem. Soc. 2009, 131, 458-460.

(21) Mondloch, J. E.; Karagiaridi, O.; Farha, O. K.; Hupp, J. T. Activation of Metal-Organic Framework Materials. CrystEngComm 2013, 15, 9258-9264.

(22) Liu, B.; Wong-Foy, A. G.; Matzger, A. J. Rapid and Enhanced Activation of Microporous Coordination Polymers by Flowing Supercritical $\mathrm{CO}_{2}$. Chem. Commun. 2013, 49, 1419-1421.

(23) Furukawa, H.; Gándara, F.; Zhang, Y.-B.; Jiang, J.; Queen, W. L.; Hudson, M. R.; Yaghi, O. M. Water Adsorption in Porous Metal-Organic Frameworks and Related Materials. J. Am. Chem. Soc. 2014, 136, 4369-4381.

(24) Jin, S.; Furukawa, K.; Addicoat, M.; Chen, L.; Takahashi, S.; Irle, S.; Nakamura, T.; Jiang, D. Large Pore Donor-Acceptor Covalent Organic Frameworks. Chem. Sci. 2013, 4, 4505-4511.

(25) Zhao, C.; Lyu, H.; Ji, Z.; Zhu, C.; Yaghi, O. M. Ester-Linked Crystalline Covalent Organic Frameworks. J. Am. Chem. Soc. 2020, 142, 14450-14454.

(26) Emmerling, S. T.; Schuldt, R.; Bette, S.; Yao, L.; Dinnebier, R. E.; Kästner, J.; Lotsch, B. V. Interlayer Interactions as Design Tool for Large-Pore COFs. J. Am. Chem. Soc. 2021, 143, 15711-15722

(27) Zhu, D.; Verduzco, R. Ultralow Surface Tension Solvents Enable Facile COF Activation with Reduced Pore Collapse. ACS Appl. Mater. Interfaces 2020, 12, 33121-33127.

(28) Diwakara, S. D.; McCandless, G. T.; Alahakoon, S. B.; Smaldone, R. A. Synthesis of Side-Chain-Free Hydrazone-Linked Covalent Organic Frameworks through Supercritical Carbon Dioxide Activation. Organic Materials 2021, 03, 277-282.

(29) Sick, T.; Rotter, J. M.; Reuter, S.; Kandambeth, S.; Bach, N. N.; Döblinger, M.; Merz, J.; Clark, T.; Marder, T. B.; Bein, T.; Medina, D. D. Switching on and off Interlayer Correlations and Porosity in 2D Covalent Organic Frameworks. J. Am. Chem. Soc. 2019, 141, 12570-12581.

(30) Feriante, C. H.; Jhulki, S.; Evans, A. M.; Dasari, R. R.; Slicker, K.; Dichtel, W. R.; Marder, S. R. Rapid Synthesis of High Surface Area Imine-Linked 2D Covalent Organic Frameworks by Avoiding Pore Collapse During Isolation. Adv. Mater. 2020, 32, 1905776.

(31) Alahakoon, S. B.; Thompson, C. M.; Nguyen, A. X.; Occhialini, G.; McCandless, G. T.; Smaldone, R. A. An Azine-Linked Hexaphenylbenzene Based Covalent Organic Framework. Chem. Commun. 2016, 52, 2843-2845.

(32) Thompson, C. M.; Occhialini, G.; McCandless, G. T.; Alahakoon, S. B.; Cameron, V.; Nielsen, S. O.; Smaldone, R. A. Computational and Experimental Studies on the Effects of Monomer Planarity on Covalent Organic Framework Formation. J. Am. Chem. Soc. 2017, 139, 10506-10513.

Alahakoon, S. B.; McCandless, G. T.; Karunathilake, A. A. K.; Thompson, C. M.; Smaldone, R. A. Enhanced Structural Organization in Covalent Organic Frameworks Through Fluorination. Chem. Eur. J. 2017, 23, 4255-4259.

(34) Alahakoon, S. B.; Occhialini, G.; McCandless, G. T.; Karunathilake, A. A. K.; Nielsen, S. O.; Smaldone, R. A. Experimental and Theoretical Insight into the Effect of Fluorine Substituents on the Properties of Azine Linked Covalent Organic Frameworks. CrystEngComm 2017, 19, 4882-4885.

Salonen, L. M.; Medina, D. D.; Carbó-Argibay, E.; Goesten, M. G.; Mafra, L.; Guldris, N.; Rotter, J. M.; Stroppa, D. G.; Rodríguez-Abreu, C. A Supramolecular Strategy Based on Molecular Dipole Moments for High-Quality Covalent Organic Frameworks. Chem. Commun. 2016, 52, 7986-7989.

Spitler, E. L.; Koo, B. T.; Novotney, J. L.; Colson, J. W.; Uribe-Romo, F. J.; Gutierrez, G. D.; Clancy, P.; Dichtel, W. R. A 2D Covalent Organic Framework with 4.7-nm Pores and Insight into Its Interlayer Stacking. J. Am. Chem. Soc. 2011, 133, 19416-19421.

Smith, B. J.; Hwang, N.; Chavez, A. D.; Novotney, J. L.; Dichtel, W. R. Growth Rates and Water Stability of 2D Boronate Ester Covalent Organic Frameworks. Chem. Commun. 2015, 51, 7532-7535. Halder, A.; Karak, S.; Addicoat, M.; Bera, S.; Chakraborty, A.; Kunjattu, S. H.; Pachfule, P.; Heine, T.; Banerjee, R. Ultrastable Imine-Based Covalent Organic Frameworks for Sulfuric Acid Recovery: An Effect of Interlayer Hydrogen Bonding. Angew. Chem. Int. Ed. 2018, 57, 5797-5802. 
(39) Halder, A.; Ghosh, M.; Khayum M, A.; Bera, S.; Addicoat, M.; Sasmal, H. S.; Karak, S.; Kurungot, S.; Banerjee, R. Interlayer Hydrogen-Bonded Covalent Organic Frameworks as High-Performance Supercapacitors. J. Am. Chem. Soc. 2018, 140, 10941-10945.

(40) Zhao, C.; Diercks, C. S.; Zhu, C.; Hanikel, N.; Pei, X.; Yaghi, O. M. Urea-Linked Covalent Organic Frameworks. J. Am. Chem. Soc. 2018, 140, 16438-16441.

(41) Li, X.; Gao, Q.; Wang, J.; Chen, Y.; Chen, Z.-H.; Xu, H.-S.; Tang, W.; Leng, K.; Ning, G.-H.; Wu, J.; Xu, Q.-H.; Quek, S. Y.; Lu, Y.; Loh, K. P. Tuneable near White-Emissive Two-Dimensional Covalent Organic Frameworks. Nat. Commun. 2018, 9, 2335.

(42) Li, L.; Lu, F.; Xue, R.; Ma, B.; Li, Q.; Wu, N.; Liu, H.; Yao, W.; Guo, H.; Yang, W. Ultrastable TriazineBased Covalent Organic Framework with an Interlayer Hydrogen Bonding for Supercapacitor Applications. ACS Appl. Mater. Interfaces 2019, 11, 26355-26363.

Alahakoon, S. B.; Tan, K.; Pandey, H.; Diwakara, S. D.; McCandless, G. T.; Grinffiel, D. I.; DurandSilva, A.; Thonhauser, T.; Smaldone, R. A. 2D-Covalent Organic Frameworks with Interlayer Hydrogen Bonding Oriented through Designed Nonplanarity. J. Am. Chem. Soc. 2020, 142, 1298712994.

(44) Zhu, D.; Alemany, L. B.; Guo, W.; Verduzco, R. Enhancement of Crystallinity of Imine-Linked Covalent Organic Frameworks via Aldehyde Modulators. Poly. Chem. 2020, 11, 4464-4468.

(45) Haase, F.; Lotsch, B. V. Solving the COF Trilemma: Towards Crystalline, Stable and Functional Covalent Organic Frameworks. Chem. Soc. Rev. 2020, 49, 8469-8500.

(46) Doonan, C.; Riccò, R.; Liang, K.; Bradshaw, D.; Falcaro, P. Metal-Organic Frameworks at the Biointerface: Synthetic Strategies and Applications. Acc. Chem. Res. 2017, 50,1423-1432.

Chae, H. K.; Siberio-Pérez, D. Y.; Kim, J.; Go, Y.; Eddaoudi, M.; Matzger, A. J.; O’Keeffe, M.; Yaghi, 0. M.; Group, M. D. and D. A Route to High Surface Area, Porosity and Inclusion of Large Molecules in Crystals. Nature 2004, 427, 523-527.

Herbert, F. C.; Abeyrathna, S. S.; Abeyrathna, N. S.; Wijesundara, Y. H.; Brohlin, O. R.; Carraro, F.; Amenitsch, H.; Falcaro, P.; Luzuriaga, M. A.; Durand-Silva, A.; Diwakara, S. D.; Smaldone, R. A.; Meloni, G.; Gassensmith, J. J. Stabilization of Supramolecular Membrane Protein-Lipid Bilayer Assemblies through Immobilization in a Crystalline Exoskeleton. Nat. Commun. 2021, 12, 2202.

(49) Oliveira, F. L.; de S. França, A.; de Castro, A. M.; Alves de Souza, R. O. M.; Esteves, P. M.; Gonçalves, R. S. B. Enzyme Immobilization in Covalent Organic Frameworks: Strategies and Applications in Biocatalysis. ChemPlusChem 2020, 85, 2051-2066.

(50) Sun, Q.; Fu, C.-W.; Aguila, B.; Perman, J.; Wang, S.; Huang, H.-Y.; Xiao, F.-S.; Ma, S. Pore Environment Control and Enhanced Performance of Enzymes Infiltrated in Covalent Organic Frameworks. J. Am. Chem. Soc. 2018, 140, 984-992.

(51) Li, H.; Ding, J.; Guan, X.; Chen, F.; Li, C.; Zhu, L.; Xue, M.; Yuan, D.; Valtchev, V.; Yan, Y.; Qiu, S.; Fang, Q. Three-Dimensional Large-Pore Covalent Organic Framework with Stp Topology. J. Am. Chem. Soc. 2020, 142, 13334-13338.

Benyettou, F.; Kaddour, N.; Prakasam, T.; Das, G.; Sharma, S. K.; Thomas, S. A.; Bekhti-Sari, F.; Whelan, J.; Alkhalifah, M. A.; Khair, M.; Traboulsi, H.; Pasricha, R.; Jagannathan, R.; Mokhtari-Soulimane, N.; Gándara, F.; Trabolsi, A. In Vivo Oral Insulin Delivery via Covalent Organic Frameworks. Chem. Sci. 2021, 12, 6037-6047.

(53) Carlsson, N.; Gustafsson, H.; Thörn, C.; Olsson, L.; Holmberg, K.; Åkerman, B. Enzymes Immobilized in Mesoporous Silica: A Physical-Chemical Perspective. Adv. Colloid Interface Sci. 2014, 205, 339-360.

(54) GößI, D.; Singer, H.; Chiu, H.-Y.; Schmidt, A.; Lichtnecker, M.; Engelke, H.; Bein, T. Highly Active Enzymes Immobilized in Large Pore Colloidal Mesoporous Silica Nanoparticles. New J. Chem. 2019, 43, 1671-1680.

(55) Liang, W.; Carraro, F.; Solomon, M. B.; Bell, S. G.; Amenitsch, H.; Sumby, C. J.; White, N. G.; Falcaro, P.; Doonan, C. J. Enzyme Encapsulation in a Porous Hydrogen-Bonded Organic Framework. J. Am. Chem. Soc. 2019, 141, 14298-14305. 
(56) Bacakova, L.; Vandrovcova, M.; Kopova, I.; Jirka, I. Applications of Zeolites in Biotechnology and Medicine - a Review. Biomater. Sci. 2018, 6, 974-989.

(57) Fujita, D.; Suzuki, R.; Fujii, Y.; Yamada, M.; Nakama, T.; Matsugami, A.; Hayashi, F.; Weng, J.-K.; YagiUtsumi, M.; Fujita, M. Protein Stabilization and Refolding in a Gigantic Self-Assembled Cage. Chem 2021.

(58) Pédelacq, J.-D.; Cabantous, S.; Tran, T.; Terwilliger, T. C.; Waldo, G. S. Engineering and Characterization of a Superfolder Green Fluorescent Protein. Nat. Biotechnol. 2006, 24, 79-88.

(59) Luzuriaga, M. A.; Benjamin, C. E.; Gaertner, M. W.; Lee, H.; Herbert, F. C.; Mallick, S.; Gassensmith, J. J. ZIF-8 Degrades in cell media, serum, and some-but not all-common laboratory buffers. Supramol. Chem. 2019, 31, 485-490.

(60) Tutol, J. N.; Kam, H. C.; Dodani, S. C. Identification of mNeonGreen as a pH-Dependent, Turn-On Fluorescent Protein Sensor for Chloride. ChemBioChem 2019, 20,1759-1765.

(61) Uribe-Romo, F. J.; Doonan, C. J.; Furukawa, H.; Oisaki, K.; Yaghi, O. M. Crystalline Covalent Organic Frameworks with Hydrazone Linkages. J. Am. Chem. Soc. 2011, 133, 11478-11481. 


\section{Supplementary Information}

\section{Supramolecular Reinforcement of a Large-Pore 2D Covalent Organic Framework}

Shashini D. Diwakara, Whitney S. Y. Ong, Yalini H. Wijesundara, Robert L. Gearhart, Fabian C. Herbert, Sarah G. Fisher, Gregory T. McCandless, Sampath B. Alahakoon, Jeremiah J. Gassensmith, Sheel C. Dodani, Ronald A. Smaldone*

\begin{tabular}{|c|}
\hline${ }^{\star}$ Corresponding Address \\
\hline Professor Ronald A. Smaldone \\
Department of Chemistry and Biochemistry \\
The University of Texas at Dallas \\
800 W. Campbell Road Richardson, Texas \\
75080 \\
Tel: $(+1)-972-883-6342$ \\
E-mail: ronald.smaldone@utdallas.edu \\
\hline
\end{tabular}




\section{Table of Contents}

1. General Methods and Instrumentation.............................................................. S2

1.1 Nuclear magnetic resonance (NMR) spectroscopy ................................. S2

1.2 Matrix-assisted laser desorption/ionization-time of flight (MALDI-TOF) mass spectrometry ............................................................................................ S2

1.3Fourier -transform infrared (FT-IR) spectroscopy........................................ S2

1.4 Powder X-ray diffraction (PXRD) analysis.................................................... S2

1.5Surface area analysis.................................................................................. S2

1.6 Supercritical carbon dioxide $\left(\mathrm{scCO}_{2}\right)$ activation...................................... S2

1.7 Scanning electron microscopy (SEM) ...................................................... S3

1.8 Transmission electron microscopy (TEM) ................................................. S3

2. Synthesis and Characterization of Monomers................................................ S3

2.1 Synthesis of monomer (1) ........................................................................ S3

2.2Synthesis of monomer (2) ...................................................................... S4

2.3 Synthesis of 4,4'-(pyrene-2,7-diyl)dianiline (3)....................................... S4

3. Synthesis and Characterization of COFs..................................................... S6

3.1 Synthesis of PyCOFamide.......................................................................... S6

3.2 Synthesis of polymer 4.......................................................................... S7

3.3 FT-IR of polymer 4............................................................................ S8

3.4 Nitrogen adsorption isotherms of conventionally activated COFs. $\quad$ S9

4. Computational Modeling of PyCOFamide....................................................... S9

5. Stability Studies of PyCOFamide............................................................... S10

6. Digestion Experiment of PyCOFamide........................................................... $\$$

7. Synthesis and Characterization of COF-42.................................................. $\$ 11$

7.1 Synthesis of 1,3,5-triformylbenzene benzene......................................... $\$$ S11

7.2 Synthesis of 2,5-diethoxyterephalodihydrazide........................................ $\quad \mathrm{S} 11$

7.3 Synthesis of COF-42 .................................................................................. $\mathrm{S} 12$

7.4FT-IR characterization of COF-42 .......................................................... $\mathrm{S} 12$

7.5 Nitrogen isotherm and pore size distribution of COF-42 ....................... S13

7.6 PXRD pattern of COF-42 ............................................................................. 513

8. Protein Loading Experiments........................................................................... S14

8.1 Protein expression and dimension measurements of protein structure S14

8.2 Protein loading into PyCOFamide and COF-42......................................... S14

8.3 Epifluorescence microscopy....................................................................... 514

9. References........................................................................................................... S18 


\section{General Methods and Instrumentation}

All the reagents including mesitylene, liquid bromine, potassium acetate, potassium permanganate, thionyl chloride, hexylamine, pyridine, 4-formylphenylboronic acid, tetracyanoquinodimethane, toluene, 1,4-dioxane, 2,7-dibromopyrene, 4aminophenylboronic acid pinacol ester, and tetrakis(triphenylphosphine)palladium(0) were purchased from commercial suppliers (Acros Organics, ASTA TED, Fisher Scientific, and Boron Molecular) and used as received without further purification. Corning Cell Culture Phosphate-Buffered Saline (1X PBS, pH 7.4) was purchased from Fisher Scientific. Formvar/Carbon Film 300 mesh Copper Grids were purchased from Electronic Microscopy Sciences.

\subsection{NMR spectroscopy}

${ }^{1} \mathrm{H}$ and ${ }^{13} \mathrm{C}$ NMR spectra for all the compounds synthesized in this study were carried out on a Bruker Avance III HD 600 MHz NMR spectrometer.

\subsection{MALDI-TOF mass spectrometry}

MALDI-TOF analysis of 4,4'-(pyrene-2,7-diyl)dianiline (3) was carried out on Shimadzu Biotech Axima Confidence spectrometer. Tetracyanoquinodimethane (TCNQ) was used as a matrix. The general procedure for sample preparation was carried out as follows: TCNQ (10 mg) and $3(1 \mathrm{mg}$ ) were grounded in a mortar to form a uniform solid, and then $1 \mathrm{~mL}$ of dichloromethane was added into the mortar to make suspension. The resulting suspension was then spotted onto the MALDI plate and analyzed with reflection mode.

\subsection{FT-IR spectroscopy}

Transmission FTIR spectra of COFs and stating monomers were taken with an attenuated total reflectance (ATR) method on a Cary 600 Series FT-IR spectrophotometer at room temperature.

\subsection{PXRD analysis}

PXRD patterns of all COFs were collected from a Bruker D8 Advance diffractometer with a sealed tube radiation source ( $\mathrm{Cu} K a, \lambda=1.54184 \AA$ ), a low background sample holder, and Lynxeye XE detector. Data were collected on a range of $2 \theta 2-30^{\circ}$.

\subsection{Surface area analysis}

Micromeritics ASAP 2020 surface area analyzer was used to collect low pressure $\mathrm{N}_{2}$ adsorption-desorption (up to 760 torr) isotherms of COFs. Ultra-high purity grade $\mathrm{N}_{2}$ gas was purchased from Airgas Corporation. $\mathrm{SCO}_{2}$ activated samples were analyzed using a liquid $\mathrm{N}_{2}$ bath $(77 \mathrm{~K})$. The Brunauer-Emmett-Teller (BET) surface area of COFs were calculated using the data in the range of $0.01<P / P \propto 0.1$. The non-local density functional theory (NLDFT) with $\mathrm{N}_{2} @ 77 \mathrm{~K}$, (cylindrical pores in an oxide surface model) in the Micromeritics software package was used to determine the pore size distributions of COFs.

\subsection{Supercritical $\mathrm{CO}_{2}$ activation}

Supercritical $\mathrm{CO}_{2}$ activation was performed using a Leica EM CPD 300 Critical Point Dryer. After isolating COF powder, it was washed with tetrahydrofuran and ethanol. The wet 
samples were kept in sample holder and introduced into the sample chamber. During filtration and washing, care was taken to avoid complete drying the COF powder. The wet samples were activated with $\mathrm{scCO}_{2}$ Program parameters: cooling temperature to keep $\mathrm{CO}_{2}$ fluid was $17^{\circ} \mathrm{C}$, the speed of $\mathrm{CO}_{2}$ influx in pressure chamber was set to slow, the exchange speed was set at 5 and the number of cycles was set to 99 . The heating speed for critical point was set to medium, the temperature was set at $35^{\circ} \mathrm{C}$, and the gas release speed was set to medium.

\subsection{SEM}

SEM images were obtained on a Zeiss Supra 40 Scanning Electron Microscope (Carl Zeiss Microscopy) at $2.50 \mathrm{kV}$. Briefly, COF powder was mounted on $15 \mathrm{~mm}$ aluminum stubs using double-sided adhesive copper tapes. Sample was sputtered with $\sim 40 \AA \mathrm{Au}$ layer before imaging.

\subsection{TEM}

COF powder was sonicated in methanol for $10 \mathrm{~min}$. The suspension $(\sim 5 \mu \mathrm{l})$ was drop cast onto TEM grids (Formvar/Carbon 300 Mesh) and droplets were allowed to sit on the $\mathrm{Cu}$ grid for $\sim 30$ seconds at room temperature. Then, excess solvent was dried with the aid of filter paper and sample was allowed to dry on TEM grids. Images were obtained on a JEOL JEM-1400 plus transmission-electron microscope at $120 \mathrm{kV}$.

\section{Synthesis and Characterization of Monomers}

\subsection{Synthesis of monomer (1)}

The compound 1 was synthesized as previously reported in the literature. ${ }^{1}$
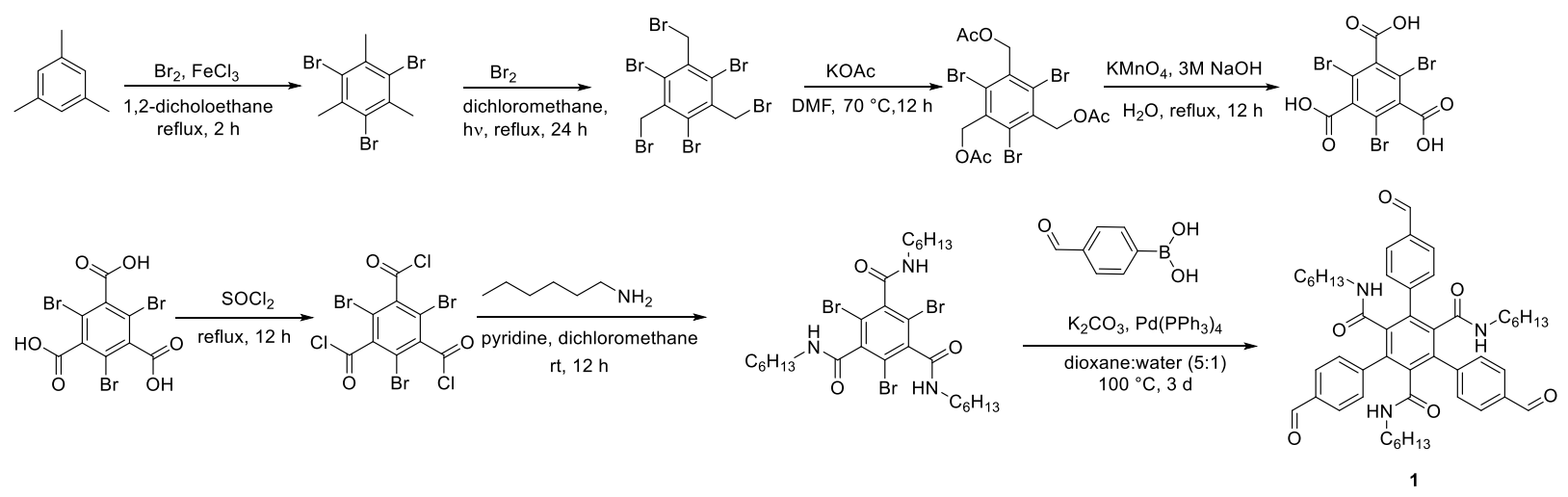

Scheme S1. Synthesis of 1. 


\subsection{Synthesis of monomer 2}

The compound 2 was synthesized as previously reported in the literature. ${ }^{2}$

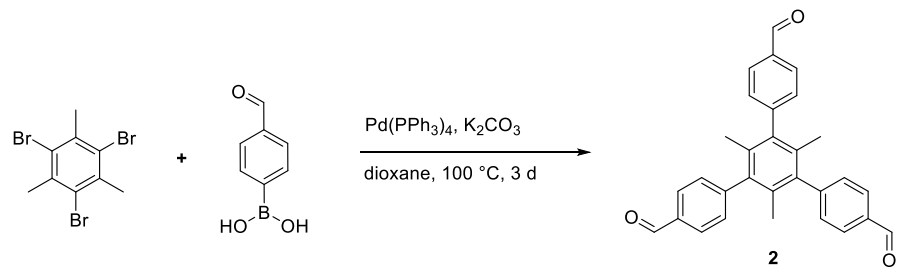

Scheme S2. Synthesis of 2.

\subsection{Synthesis of 4,4'-(pyrene-2,7-diyl)dianiline (3)}

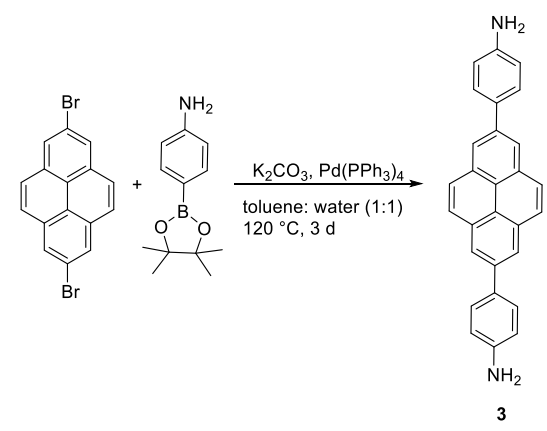

Scheme S3. Synthesis of 3.

To a pressure sealed tube, a mixture of water $(2.5 \mathrm{~mL})$ and toluene $(2.5 \mathrm{~mL})$ was placed along a stirring bar. The solvent mixture was degassed with $\mathrm{N}_{2}$ for $15 \mathrm{~min}$. Then, 2,7dibromopyrene ( $250 \mathrm{mg}, 0.694 \mathrm{mmol}$ ), 4-aminophenylboronic acid pinacol ester (335 $\mathrm{mg}$, $1.53 \mathrm{mmol}), \mathrm{K}_{2} \mathrm{CO}_{3}(1.44 \mathrm{~g}, 10.41 \mathrm{mmol}), \mathrm{Pd}\left(\mathrm{PPh}_{3}\right)_{4}(80 \mathrm{mg}, 0.1 \mathrm{mmol})$ were added into the pressure tube. After that, the tube was sealed and stirred at $120^{\circ} \mathrm{C}$ for $3 \mathrm{~d}$. After the completion of reaction, the mixture was cooled to room temperature and quenched with water. Then, the resulted precipitate was filtered off and washed with copious amount of water followed by ethyl acetate and acetone to obtain pure product of 3 as pale-yellow powder with $64 \%$ yield. ${ }^{1} \mathrm{H} \mathrm{NMR}\left(600 \mathrm{MHz}\right.$, DMSO- $\left.d_{6}\right): \delta(\mathrm{ppm})=8.44(\mathrm{~s}, 4 \mathrm{H}), 8.17(\mathrm{~s}, 4 \mathrm{H})$, $7.71(\mathrm{~d}, J=6.00 \mathrm{~Hz}, 4 \mathrm{H}), 6.77(\mathrm{~d}, J=6.00 \mathrm{~Hz}, 4 \mathrm{H}), 5.33(\mathrm{~s}, 4 \mathrm{H}) .{ }^{13} \mathrm{C}$ NMR $(600 \mathrm{MHz}$, DMSO$\left.d_{6}\right): \delta(\mathrm{ppm})=149.12,138.83,131.39,128.51,128.13,127.86,122.73,122.50,114.93$. MALDI-TOF-MS $m / z$ for $\mathrm{C}_{28} \mathrm{H}_{20} \mathrm{~N}_{2}$ (calculated: 384.48 ), found: 384.58 . 

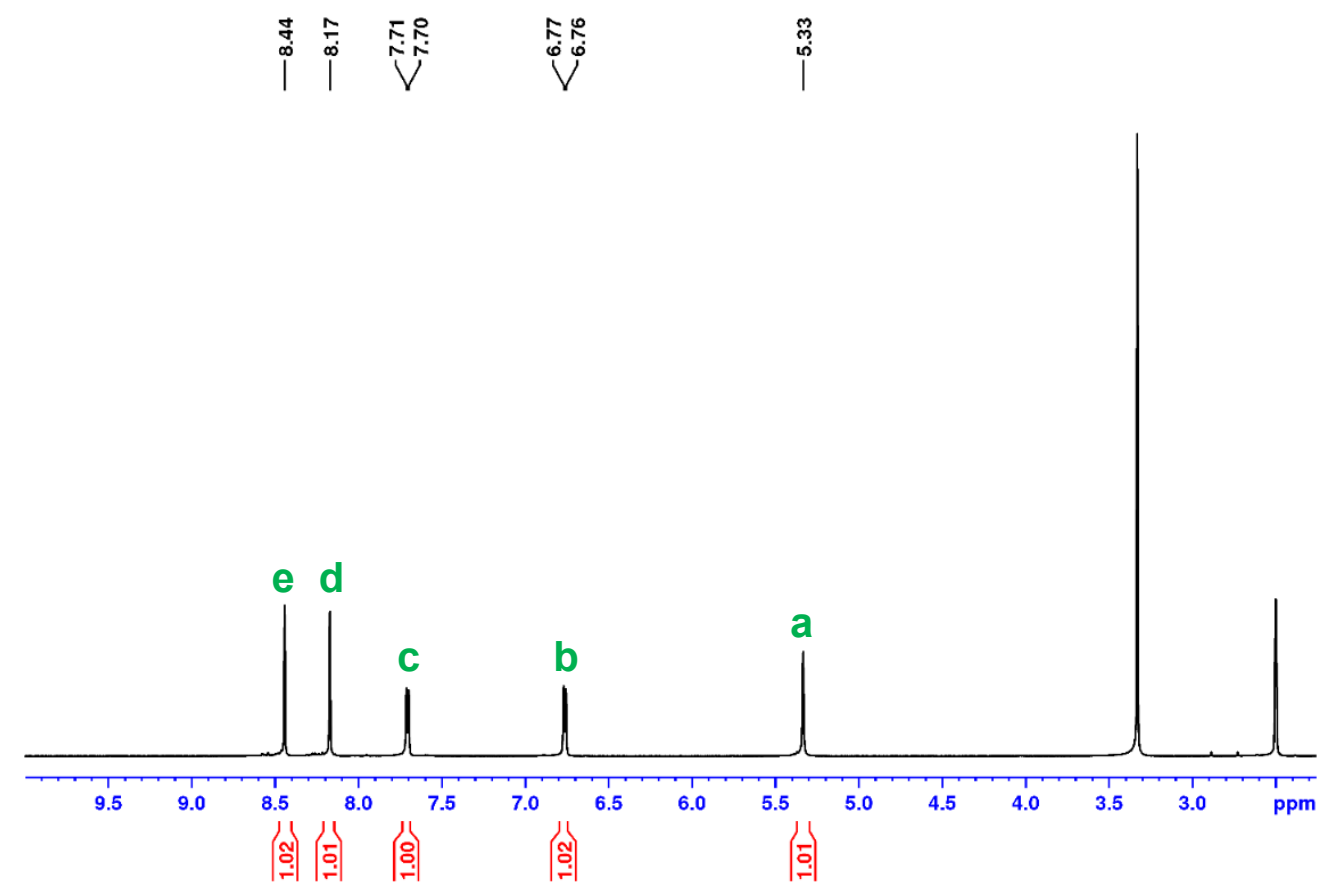

Figure S1. ${ }^{1} \mathrm{H}$ NMR spectrum of 4,4'-(pyrene-2,7-diyl)dianiline (3) in DMSO- $d_{6}$.

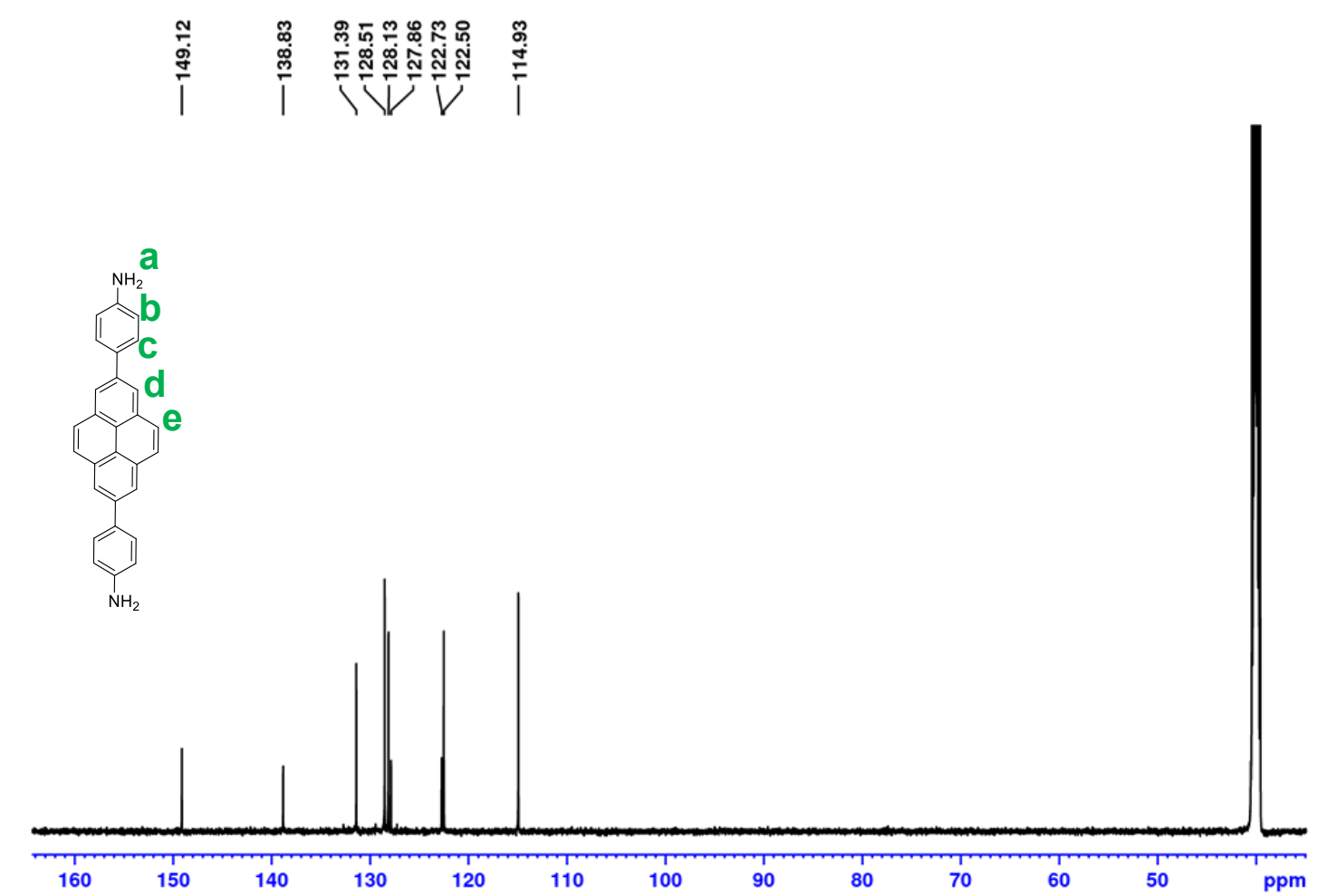

Figure S2. ${ }^{13} \mathrm{C}$ NMR spectrum of 4,4'-(pyrene-2,7-diyl)dianiline (3) in DMSO- $d_{6}$. 


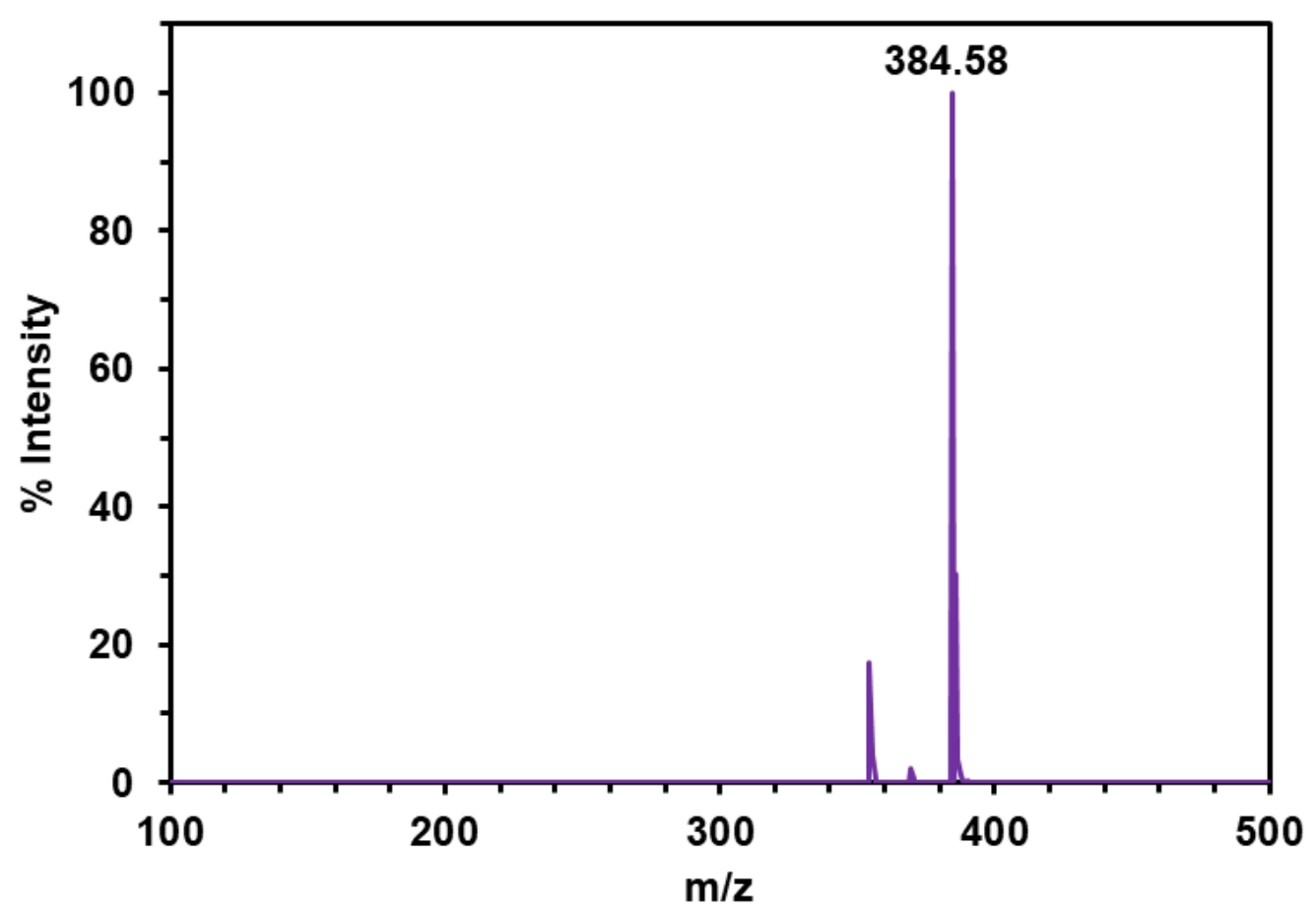

Figure S3. MALDI-TOF spectrum of monomer 3.

\section{Synthesis and Characterization of COFs}

\subsection{Synthesis of PyCOFamide}

To a $5 \mathrm{~mL}$ ampoule was added 1 (15 mg, $0.019 \mathrm{mmol}$ ) and $3(11.2 \mathrm{mg}, 0.065 \mathrm{mmol})$ along with $o$-dichlorobenzene $(1.9 \mathrm{~mL})$ and $n$-butanol $(0.1 \mathrm{~mL})$. The mixture was sonicated for $10 \mathrm{~min}$ followed by addition of aqueous acetic acid $(3 \mathrm{M}, 0.1 \mathrm{~mL})$ before being flash frozen in liquid nitrogen bath (at $77 \mathrm{~K}$ ) and flame sealed. Once the ampoule was warmed to room temperature, it was kept in an oven at $120^{\circ} \mathrm{C}$ for $5 \mathrm{~d}$ without any disturbances. After that, the ampoule was cooled to room temperature and the precipitate was collected by filtration. The resulted solid was washed with neat THF $(10 \mathrm{~mL})$ and ethanol $(10 \mathrm{~mL})$. Then, the wet filter cake was subjected to $\mathrm{ScCO}_{2}$ activation to afford $15 \mathrm{mg}$ (65\% yield) ash-colored powder of PyCOFamide. 


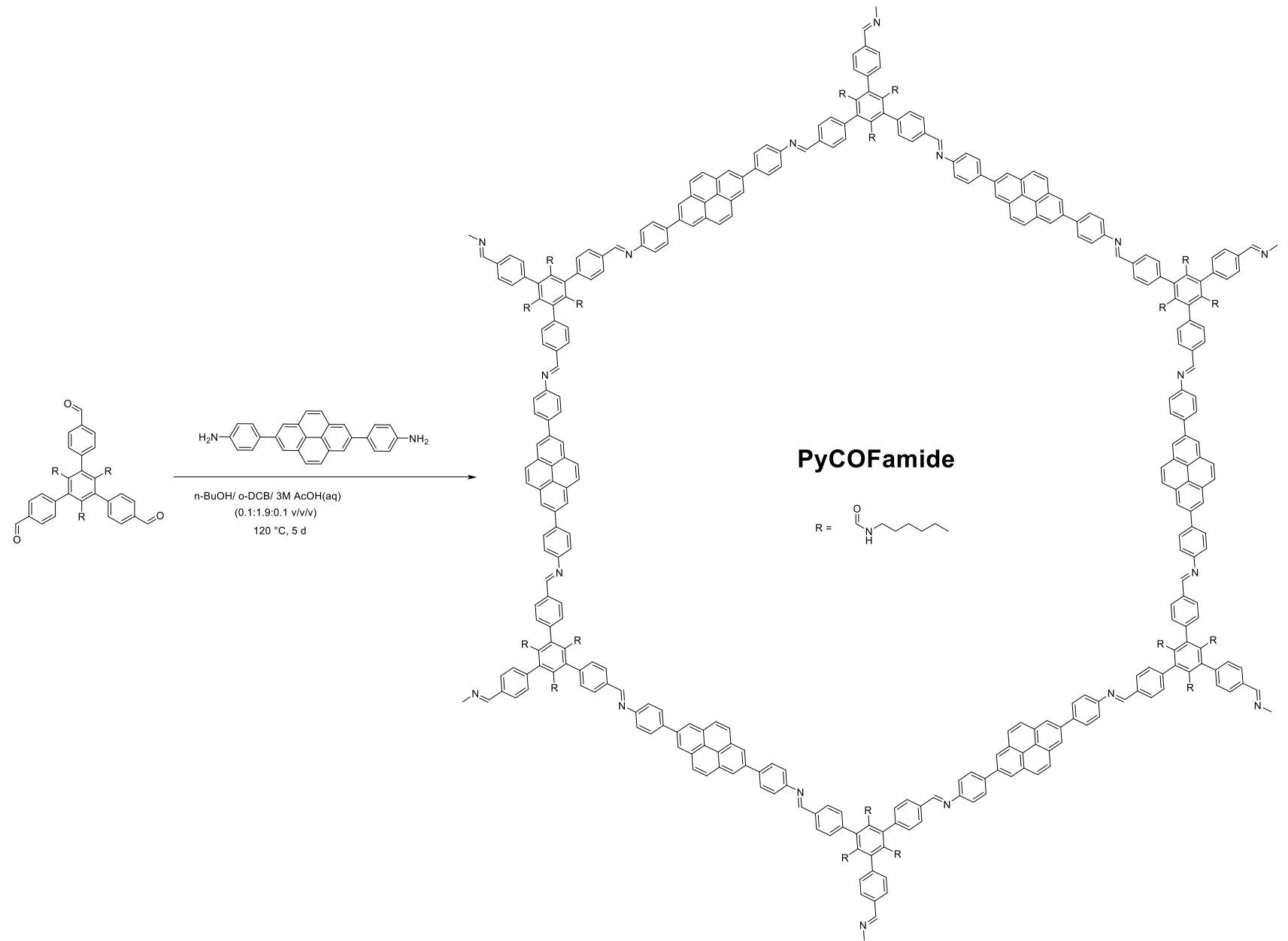

Scheme S4. Synthesis of PyCOFamide.

\subsection{Synthesis of polymer 4}

To a $5 \mathrm{~mL}$ ampoule was added $2(11.3 \mathrm{mg}, 0.026 \mathrm{mmol})$ and $3(15 \mathrm{mg}, 0.039 \mathrm{mmol}$ ) along with $o$-dichlorobenzene $(1.9 \mathrm{~mL})$ and $n$-butanol $(0.1 \mathrm{~mL})$. The mixture was sonicated for 10 min followed by addition of aqueous acetic acid $(3 \mathrm{M}, 0.1 \mathrm{~mL})$ before being flash frozen in liquid nitrogen bath (at $77 \mathrm{~K}$ ) and flame sealed. Once the ampoule was warmed to room temperature, it was kept in an oven at $120^{\circ} \mathrm{C}$ for $5 \mathrm{~d}$ without any disturbances. After that, the ampoule was cooled to room temperature and the precipitate was collected by filtration. The resulted solid was washed with neat THF $(10 \mathrm{~mL})$ and ethanol $(10 \mathrm{~mL})$. Then, the wet filter cake was subjected to $\mathrm{scCO}_{2}$ activation to afford $11 \mathrm{mg}$ (42\% yield) pale yellow powder of polymer 4 . 


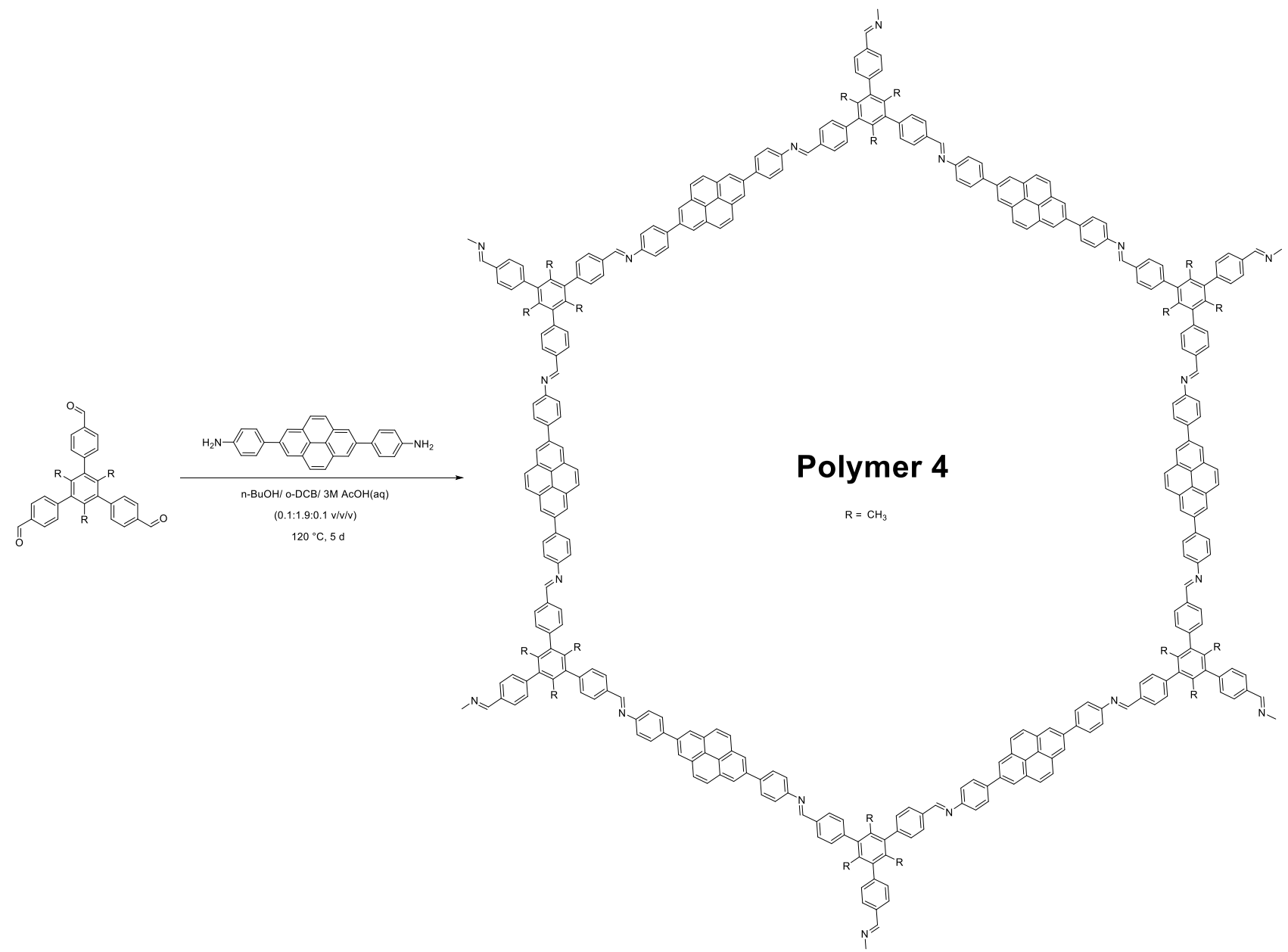

Scheme S5. Synthesis of polymer 4 .

\subsection{FT-IR of Polymer 4}

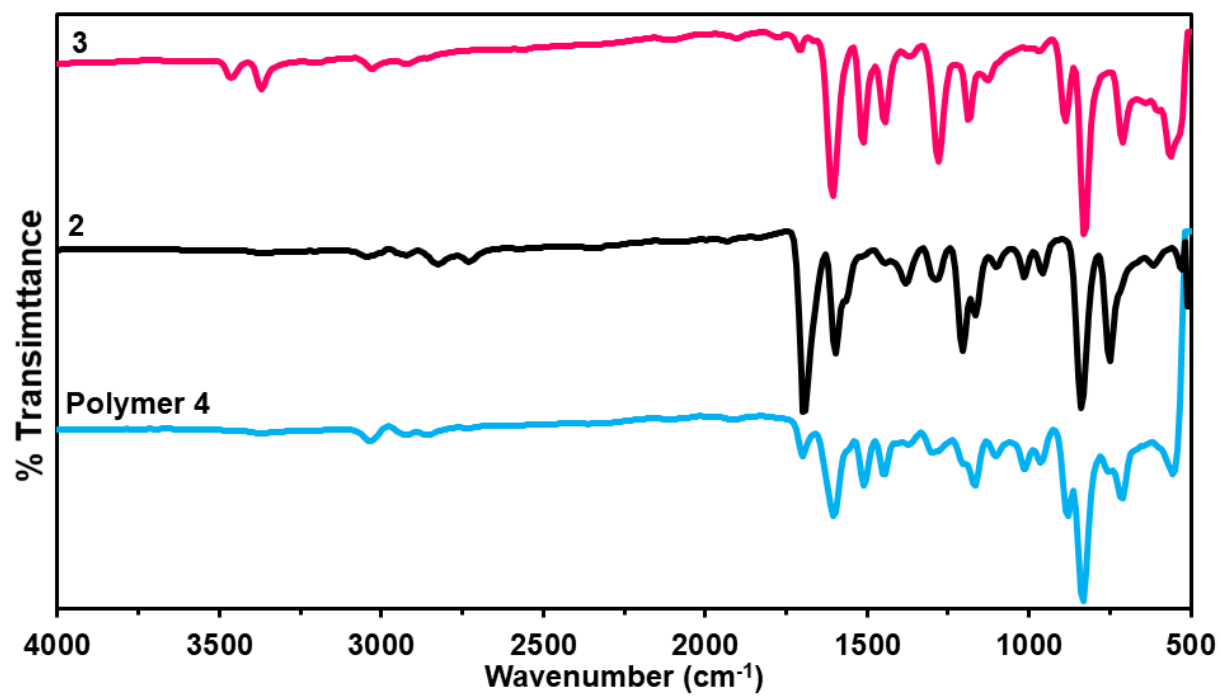

Figure S4. FT-IR spectra of $\mathrm{scCO}_{2}$ activated polymer 4 and starting monomers. 


\subsection{Nitrogen Adsorption Isotherms of Conventionally Activated COFs}

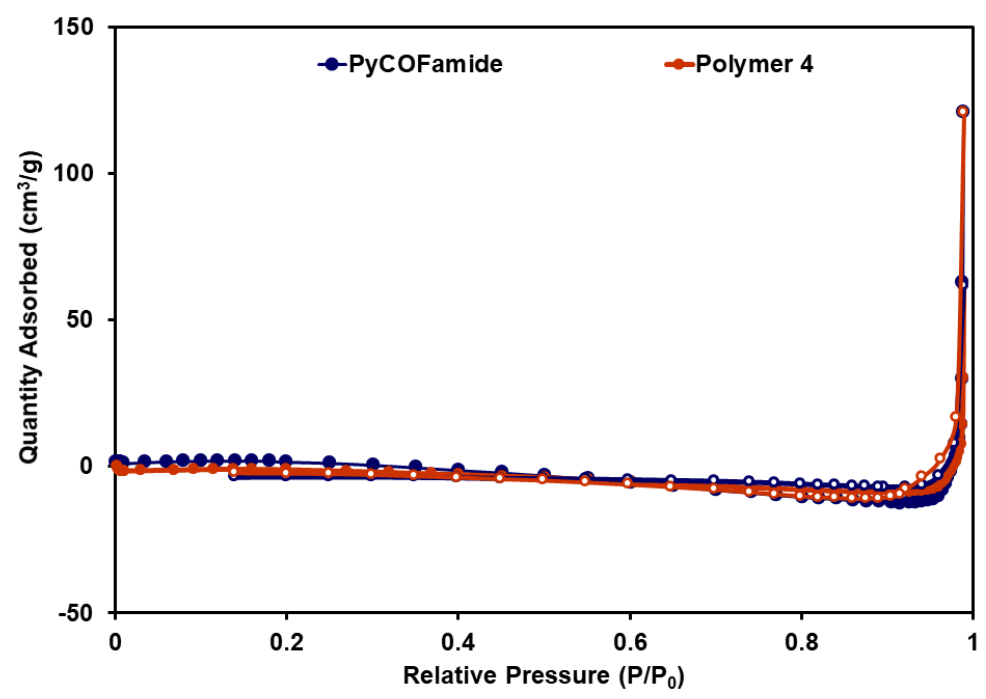

Figure S5. Nitrogen adsorption (closed circle) and desorption (open circle) isotherms of conventionally activated PyCOFamide and polymer 4.

\section{Computational Modeling of PyCOFamide}

The crystal models for all the COFs including cell parameters were built using the BIOVA Material Studio 2019 software package. The initial lattice structures with eclipsed stacking (bnn topology) layers of PyCOFamide was constructed with the space group $\mathrm{P} 6 / \mathrm{m}$. The created crystal structures were geometry optimized in P1 with the Forcite module (Smart algorithm) in Material Studio using the universal force field (UFF). The geometry optimized structures were used to generate their simulated PXRD patterns using Reflex Plus module with Pseudo-Voigt function. The refined PXRD profile was obtained by applying the profile fitting with Pawley refinement in Material Studio. The obtained lattice parameters are as follows:

$$
\begin{array}{ccc}
a=58.12 \AA, & b=60.92 \AA, & c=5.14 \AA \\
a=91.70^{\circ}, & \quad \beta=87.83^{\circ}, & Y=120.35^{\circ}
\end{array}
$$




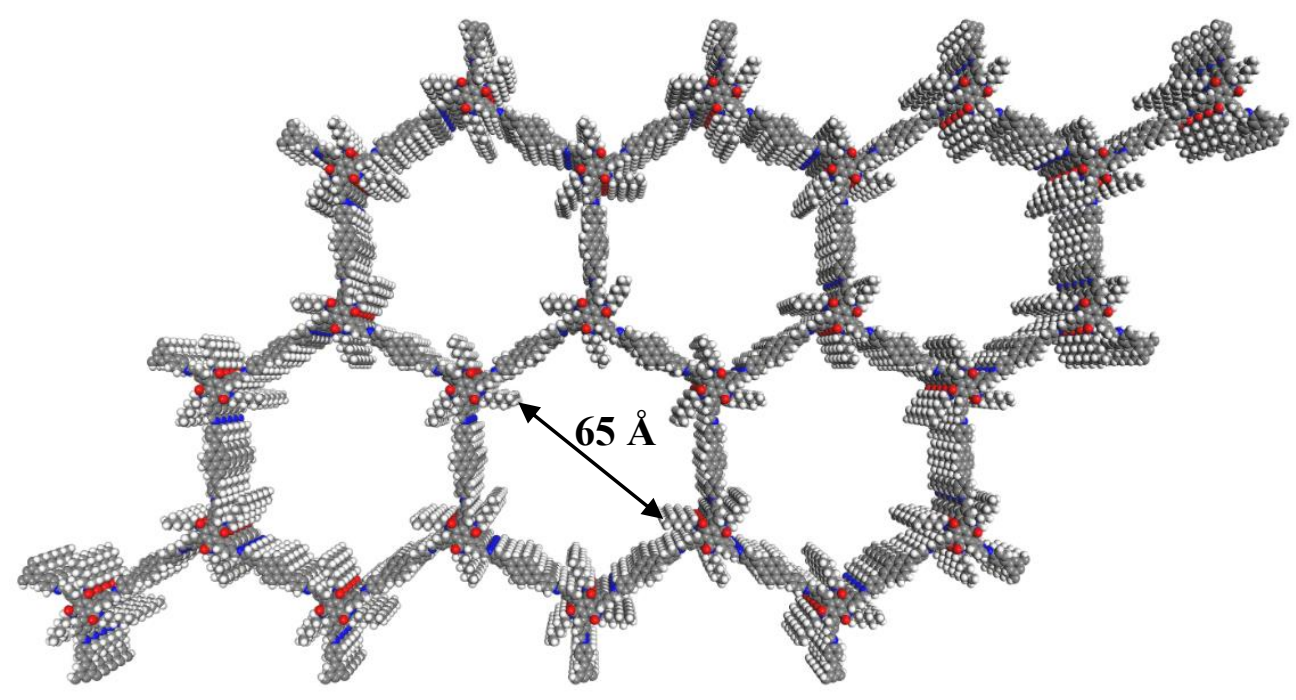

Figure S6. PyCOFamide in eclipsed (bnn topology) packing mode.

\section{Stability Studies of PyCOFamide}

PyCOFamide ( 10 mg) is directly submerged in $5 \mathrm{~mL}$ of a different solution or solvent and this was kept for a period of $3 \mathrm{~d}$ at room temperature. The COF powders were then filtered and dried. The retention of crystallinity is tested using PXRD.

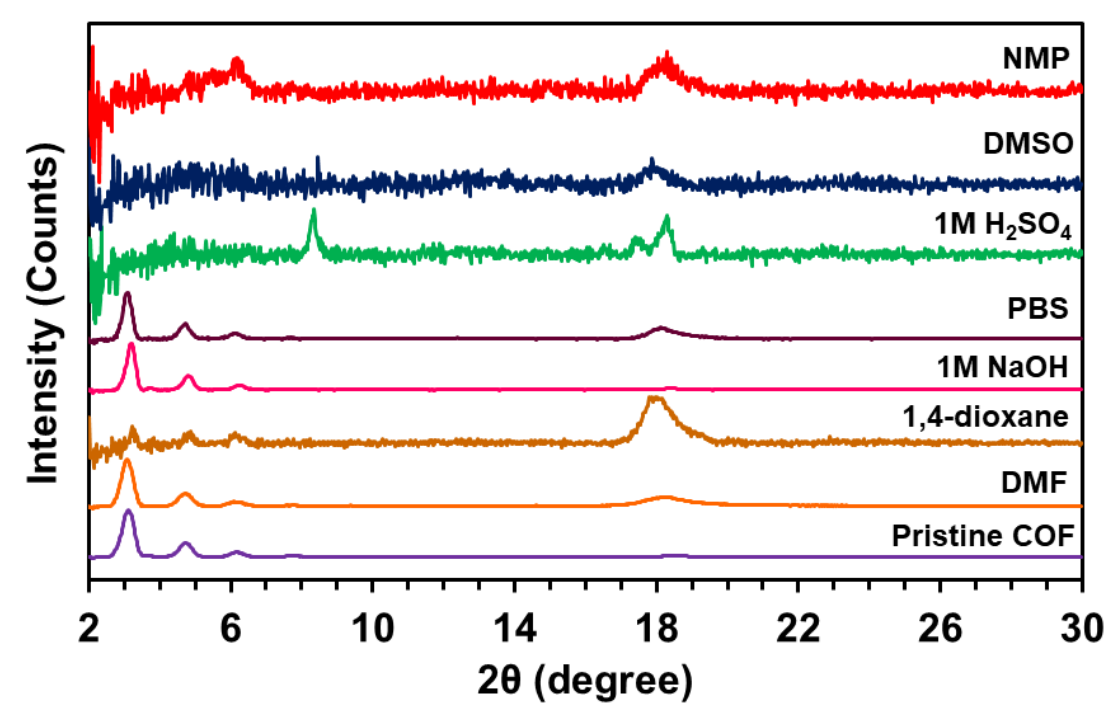

Figure S7. PXRD spectra of PyCOFamide after immersion in different solvents and solutions. 


\section{Digestion experiment of PyCOFamide}

Deuterium chloride $\left(20 \% \mathrm{w} / \mathrm{w}\right.$ ) in $\mathrm{D}_{2} \mathrm{O}$ ( 3 drops) was added into PyCOFamide powder. Then, it was heated at $120^{\circ} \mathrm{C}$ for $30 \mathrm{~s}$ followed by addition of DMSO- $d_{6}$. The obtained mixture was sonicated for 10 min and an ${ }^{1} \mathrm{H}$ NMR spectrum was collected using this sample.
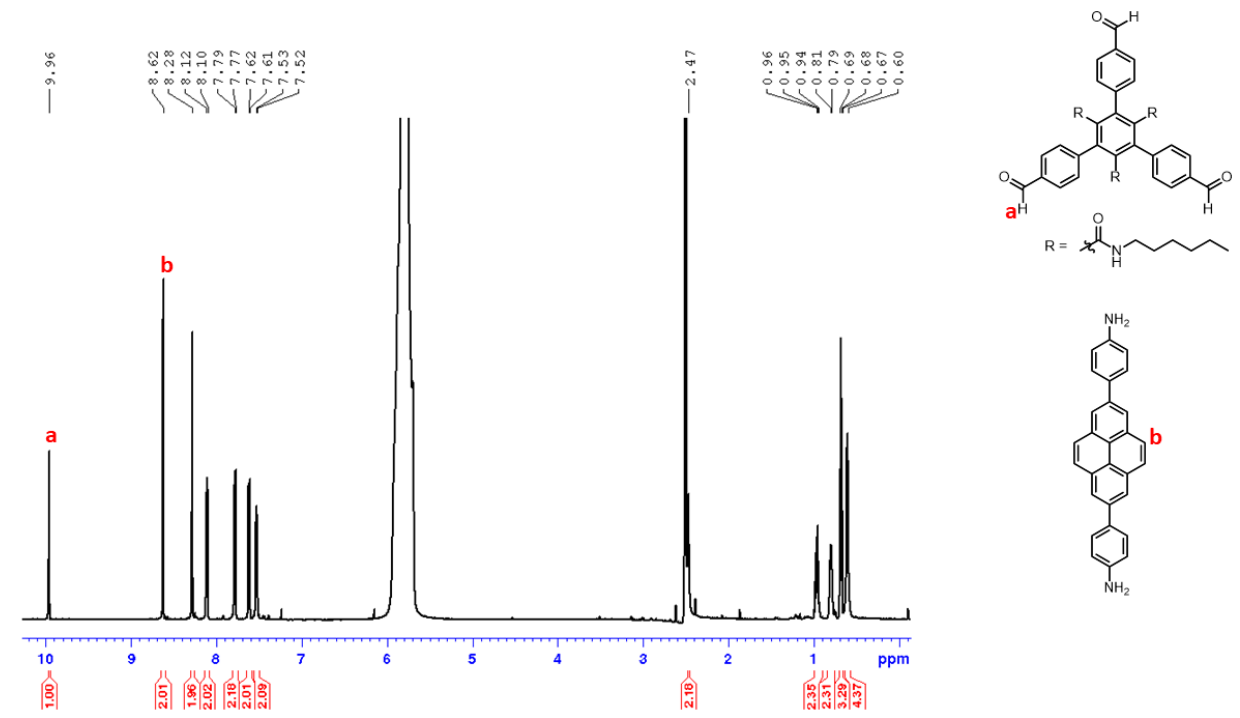

Figure S8. ${ }^{1} \mathrm{H}$ NMR spectrum of digested PyCOFamide in acidified DMSO- $d_{6}$.

\section{Synthesis and Characterization of COF-42}

\subsection{Synthesis of 1,3,5-triformylbenzene benzene}

The compound was synthesized as previously reported in the literature. ${ }^{3}$ All spectroscopic data is matched with the literature.

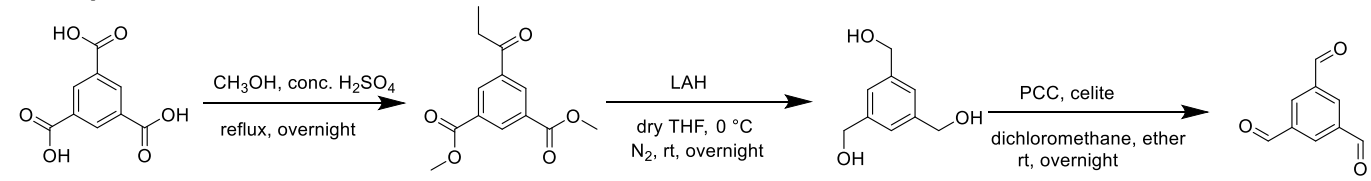

Scheme S6. Synthesis of 1,3,5-triformylbenzene.

\subsection{Synthesis of 2,5-diethoxyterephalodihydrazide}

The compound was synthesized as previously reported in the literature. ${ }^{4}$ All spectroscopic data matches literature values.

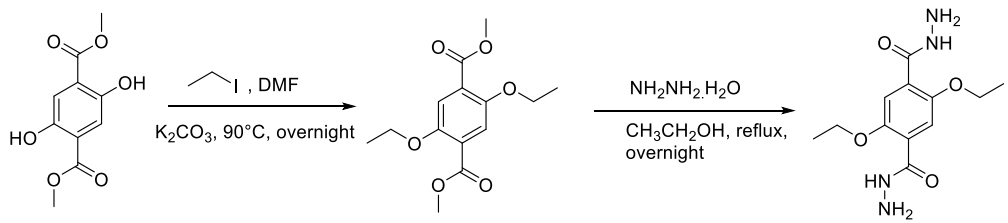

Scheme S7. Synthesis of 2,5-diethoxyterephalodihydrazide. 


\subsection{Synthesis of COF-42}

COF-42 was synthesized as previously reported in the literature. ${ }^{5}$

1,3,5-triformylbenzene $(5 \mathrm{mg}, 0.031 \mathrm{mmol}$ ) and 2,5-diethoxyterephalodihydrazide (13 $\mathrm{mg}$, $0.046 \mathrm{mmol})$ were kept in a $5 \mathrm{~mL}$ ampoule along with 1,4-dioxane $(250 \mu \mathrm{L})$ and mesitylene $(750 \mu \mathrm{L})$. Then, the mixture was sonicated for $10 \mathrm{~min}$ followed by addition of $6 \mathrm{M}$ acetic acid $(0.1 \mathrm{~mL}$, aq.) before being flash frozen in liquid nitrogen bath (at $77 \mathrm{~K}$ ) and flame sealed. Once the ampoule was warmed to room temperature, it was kept in an oven at $120{ }^{\circ} \mathrm{C}$ for $3 \mathrm{~d}$ without any disturbances. After that, the ampoule was cooled to room temperature and the precipitate was collected by filtration. The resulted solid was washed with neat THF $(10 \mathrm{~mL})$ and ethanol $(10 \mathrm{~mL})$. Then, the wet filter cake was subjected to $\mathrm{scCO}_{2}$ activation to afford $17.5 \mathrm{mg}$ (97\% yield) of a pale-yellow colored powder of COF-42.
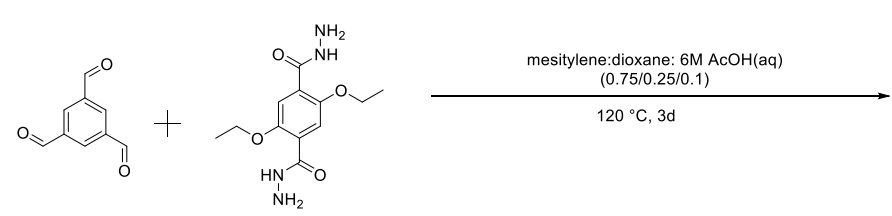

mesitylene:dioxane: $6 \mathrm{M} \mathrm{AcOH}(\mathrm{aq})$

Scheme S8. Synthesis of COF-42.

\subsection{FT-IR characterization of COF-42}

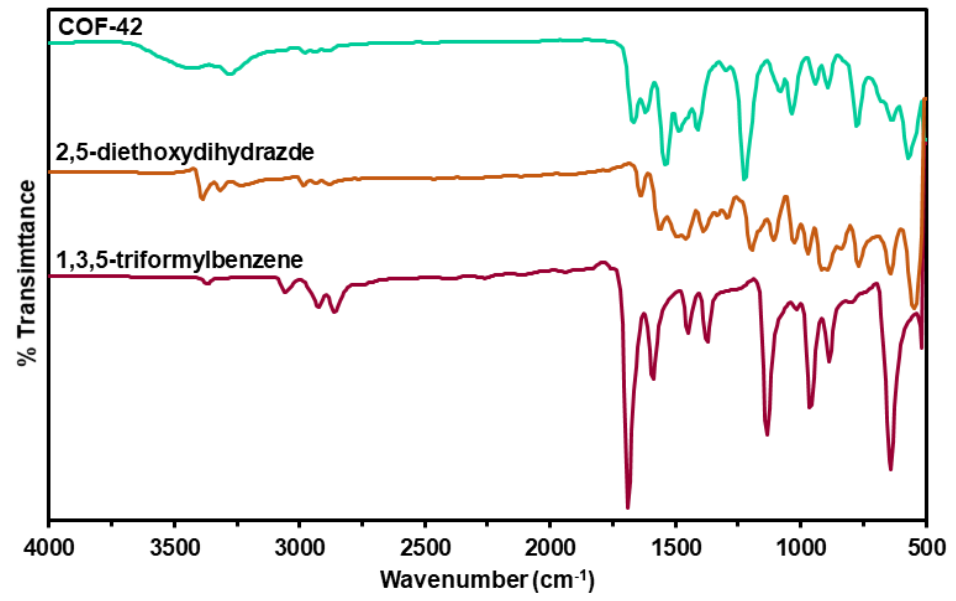

Figure S9. FT-IR spectra of COF-42 and starting monomers. 
7.5 Nitrogen Isotherm and pores size distribution of COF-42

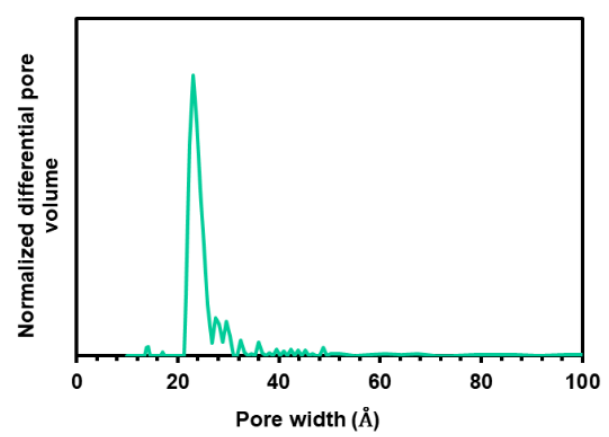

Figure S10. Pore size distribution of COF-42.

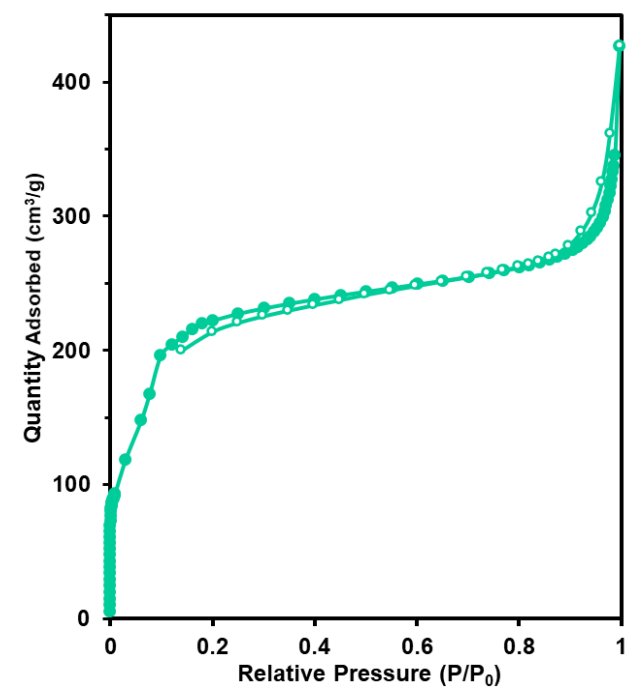

Figure S11. Nitrogen adsorption (closed circle) and desorption (open circle) isotherm of COF-42. Calculated BET surface area $=836 \mathrm{~m}^{2} / \mathrm{g}$

\subsection{PXRD pattern of COF-42}

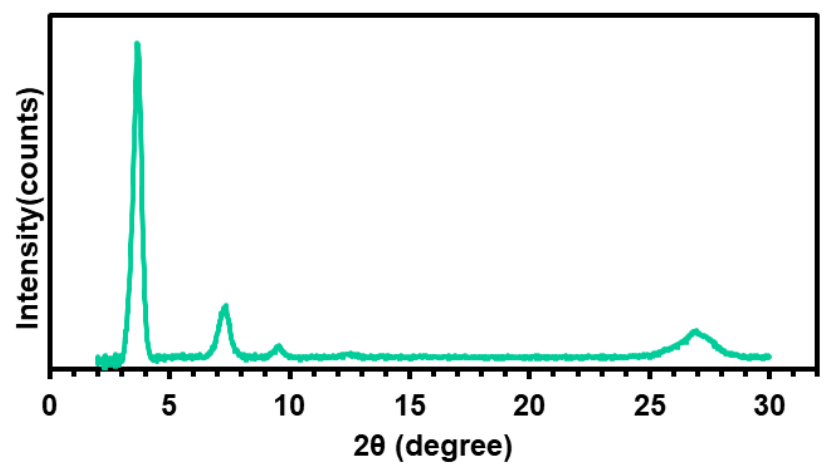

Figure S12. PXRD pattern of COF-42. 


\section{Protein Adsorption Experiments}

\subsection{Protein expression and dimension measurements of protein structure}

Superfolder Green Fluorescent Protein (sfGFP, PDB ID: 2B3P) ${ }^{6}$ and mNeonGreen (mNG, PDB ID: $5 \mathrm{LTR})^{7}$ were prepared as previously described. For $\mathrm{mNG}$, the following modifications were made: The protein was buffer exchanged into $20 \mathrm{mM}$ phosphate buffer and $200 \mathrm{mM}$ gluconate at $\mathrm{pH}$ 7. All spectroscopic measurements were carried out in 1X PBS phosphate buffered saline (PBS 1X, pH 7.4) as described below. The protein crystal structures were generated using PyMOL, and the dimensions of the proteins of proteins were measured using the following open source code: https://github.com/Pymol-Scripts/Pymol-scriptrepo/blob/master/Draw_Protein_Dimensions.py.

\subsection{Protein loading into PyCOFamide and COF-42}

Both PyCOFamide and COF-42 (1 mg) were measured into separate vials and suspended in $1 \mathrm{~mL}$ of $1 \mathrm{X}$ PBS. The vials were sonicated overnight in ultrasonic bath. Stock solutions of both sfGFP and $\mathrm{mNG}$ were prepared in $1 X$ PBS at $1.6 \mathrm{mg} / \mathrm{mL}$ and $1 \mathrm{mg} / \mathrm{mL}$, respectively. Each COF and protein were combined in $1.5 \mathrm{~mL}$ polypropylene tubes at $1: 1$, $1: 3$, and $1: 9$ ratios of COF to protein. For each ratio, as a control the protein was combined with 1X PBS instead of the COF. The tubes were then incubated in a delicase fridge with shaking for $3 \mathrm{~d}$. Following this, each sample was centrifuged for $5 \mathrm{~min}$ at $20,000 \mathrm{~g}$ at $4{ }^{\circ} \mathrm{C}$ (5810 R, Eppendorf). Three-50 $\mu \mathrm{L}$ portions of each supernatant were pipetted into 96 -well half-area plate for spectroscopic measurements on a plate reader. Absorbance of each sample was recorded from $300-700 \mathrm{~nm}$ with a $5 \mathrm{~nm}$ step size. For sfGFP excitation was provided at $460 \mathrm{~nm}$, and the emission was collected from $475-700 \mathrm{~nm}$; for $\mathrm{mNG}$ excitation was provided at $485 \mathrm{~nm}$, and the emission was collected from $500-700 \mathrm{~nm}$. For all fluorescence measurements the following settings were used: $5 \mathrm{~nm}$ step size, 30 flashes, gain of 75 , and a $z$-position at 16,000 . For each sample, the average of the three spectra are reported.

\subsection{Epifluorescence microscopy}

After obtaining fluorescence and absorbance measurements, protein loaded COF pellets were washed (4x) with 1X PBS, followed by centrifuged for 2 min at 12,100 $\mathrm{g}$ (mini Spin, Eppendorf) each time and dried in air. The dried COF pellets were used to prepare aqueous suspensions $(1 \mathrm{mg} / \mathrm{mL})$ of the samples and $10 \mu \mathrm{L}$ of each sample were loaded on to a glass microscopic slide, covered with a glass coverslip with an aid of mounting medium (Leica Surgipath MM 24). After that, the prepared specimens were imaged under EVOSFL epifluorescence microscope under epifluorescence and transmitted light (bright field and phase contrast). The fluorescence intensity was adjusted to the background and all the images were recorded at the same light intensity to be comparable with the exposure time for $10 \mathrm{~s}$. 

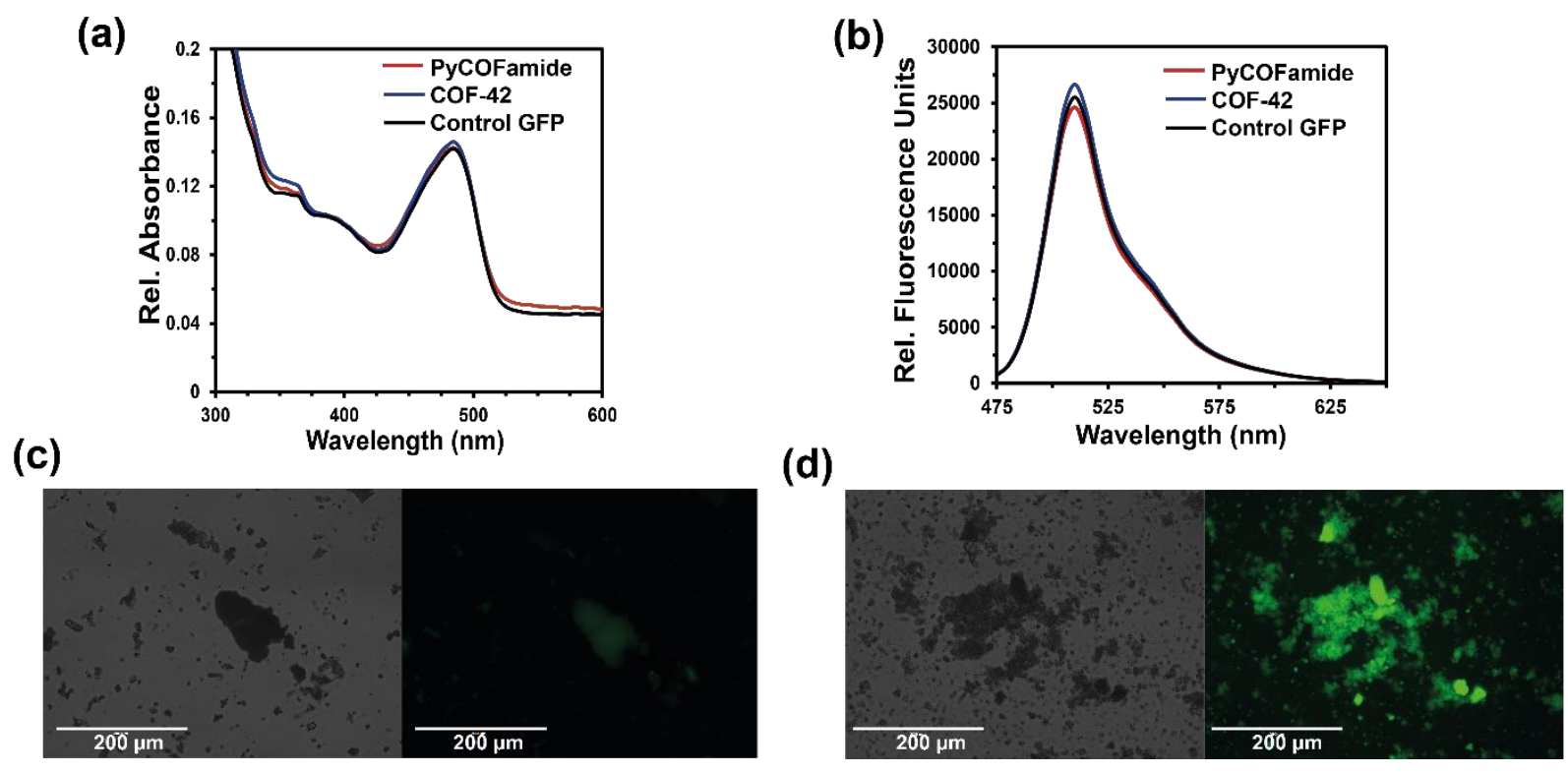

Figure S13. (a) absorbance, (b) fluorescence, (c) COF-42 fluorecence microscopic images, and (d) PyCOFamide fluorecence microscopic images for GFP:COF = 1:1 ratio.

(c)

(a)
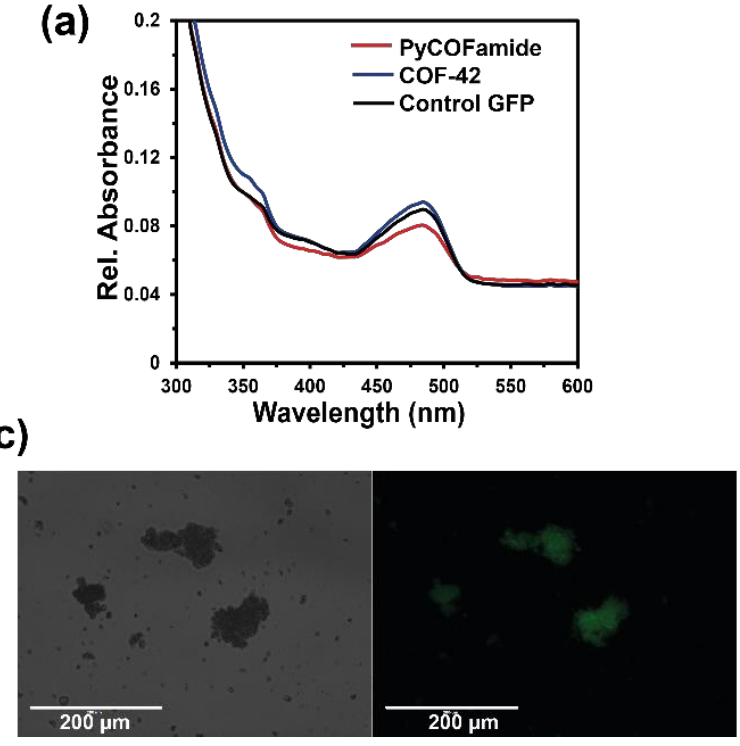

(b)

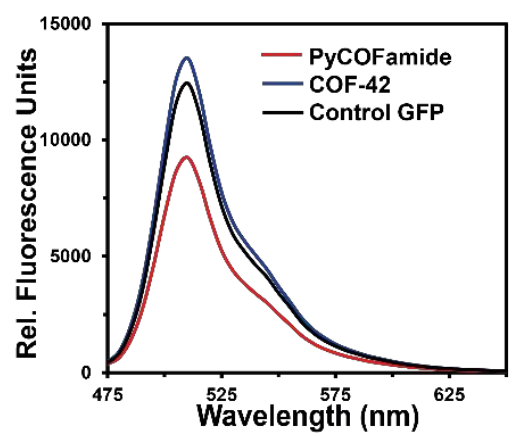

(d)

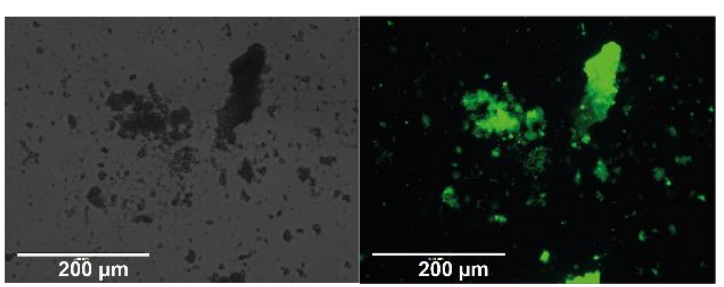

Figure S14. (a) absorbance, (b) fluorescence, (c) COF-42 fluorecence microscopic images, and (d) PyCOFamide fluorecence microscopic images for GFP:COF = 1:3 ratio. 
(a)

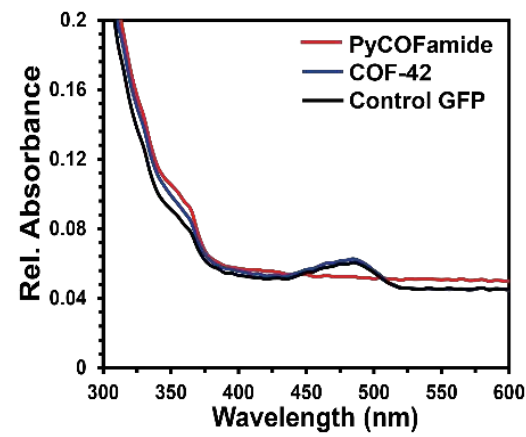

(c)

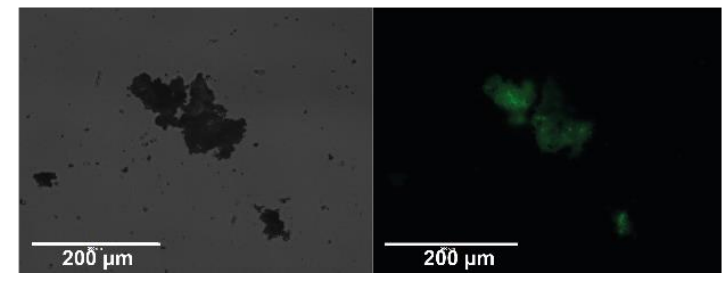

(b)

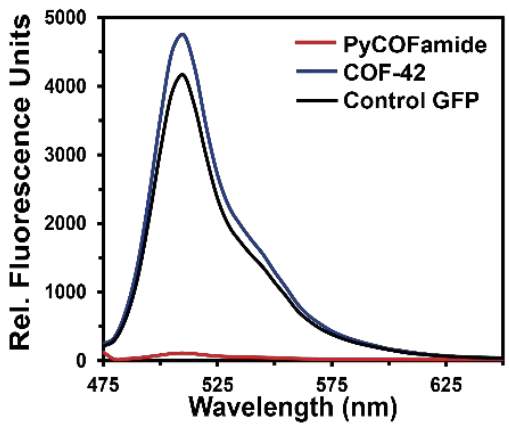

(d)

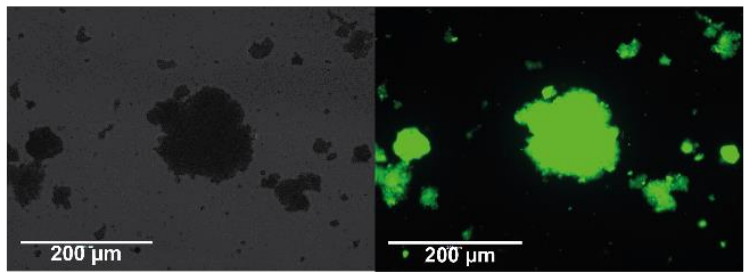

Figure S15. (a) absorbance, (b) fluorescence, (c) COF-42 fluorecence microscopic images, and (d) PyCOFamide fluorecence microscopic images for GFP:COF = 1:9 ratio.

\subsection{Loading of mNeonGreen (mNG) into PyCOFamide and COF-42}

(a)

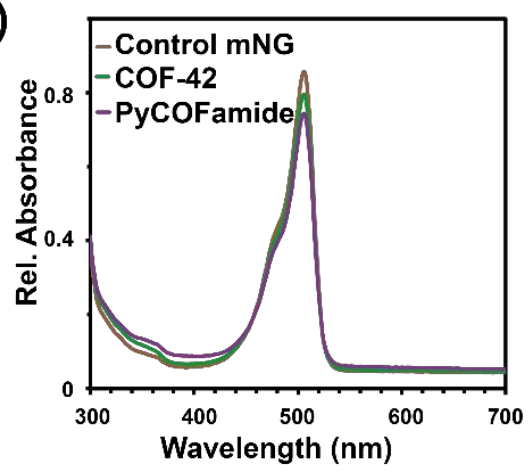

(c)

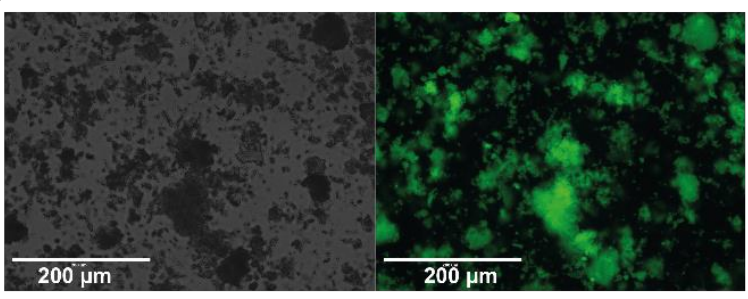

(b)

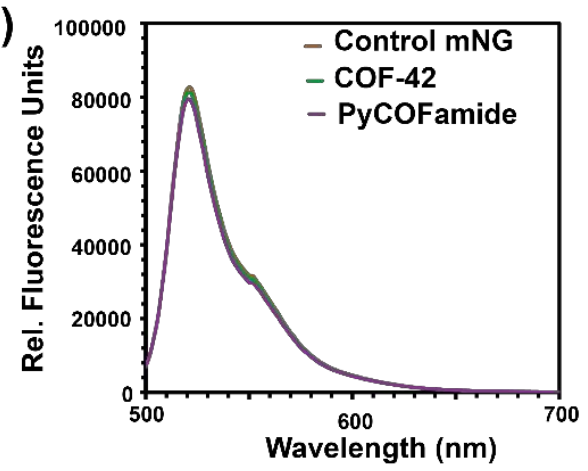

(d)

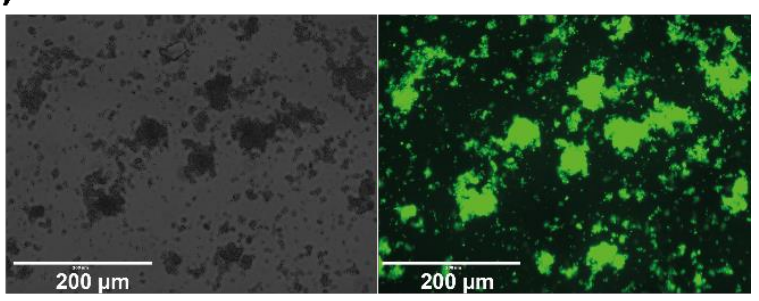

Figure S16. (a) absorbance, (b) fluorescence, (c) COF-42 fluorecence microscopic images, and (d) PyCOFamide fluorecence microscopic images for mNG:COF = 1:1 ratio. 
(a)

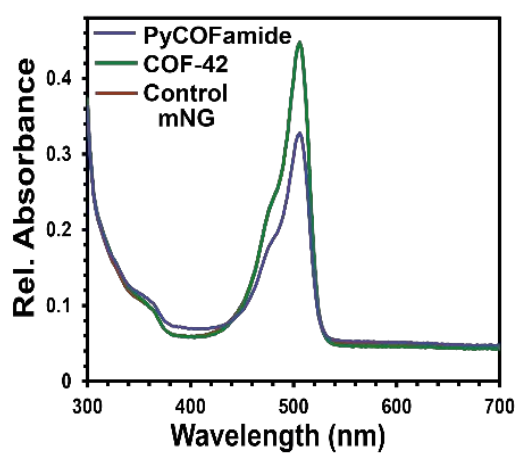

(c)

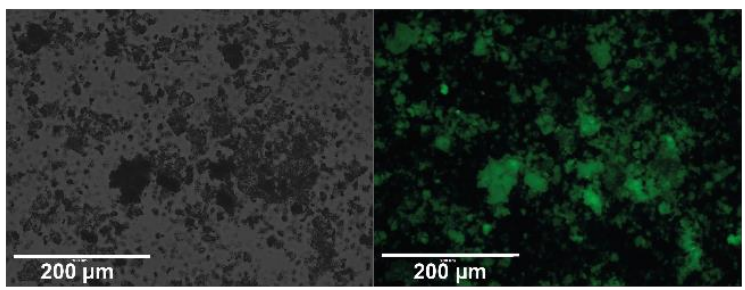

(b)

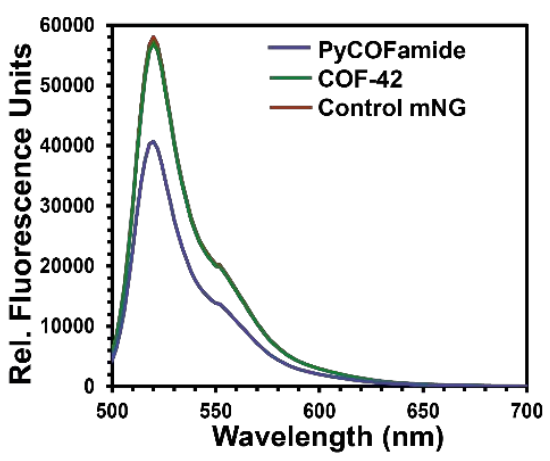

(d)

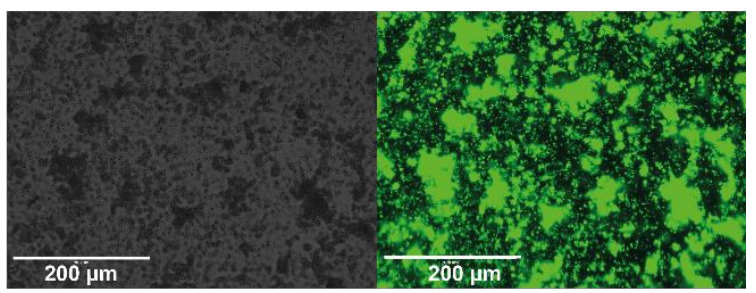

Figure S17. (a) absorbance, (b) fluorescence, (c) COF-42 fluorecence microscopic images, and (d) PyCOFamide fluorecence microscopic images for mNG:COF = 1:3 ratio.

(c)

(a)

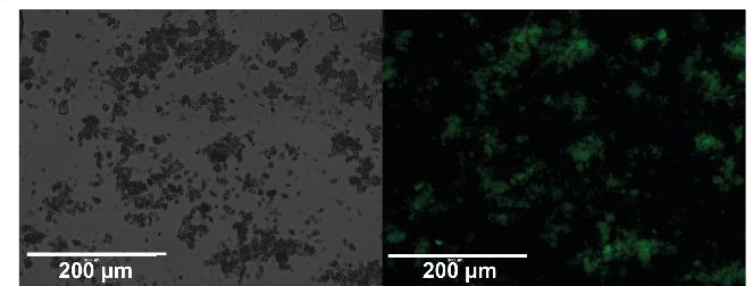

(b)

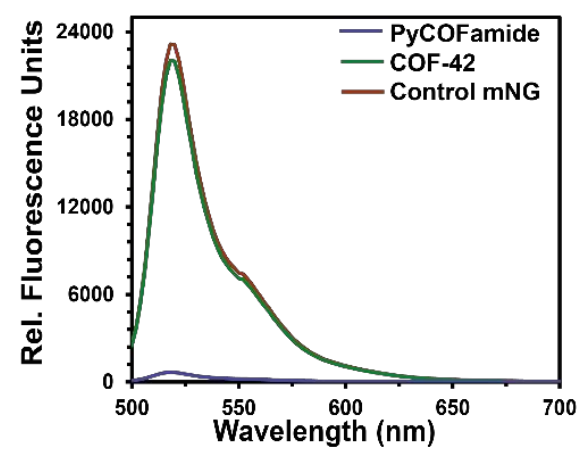

(d)

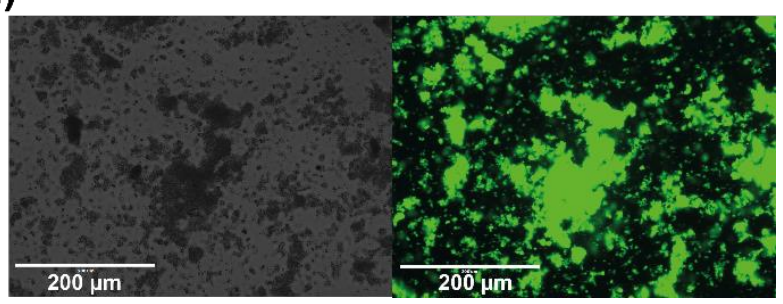

Figure S18. (a) absorbance, (b) fluorescence, (c) COF-42 fluorecence microscopic images, and (d) PyCOFamide fluorecence microscopic images for $\mathrm{mNG}: \mathrm{COF}=$ 1:9 ratio. 


\section{References}

(1) Alahakoon, S. B.; Tan, K.; Pandey, H.; Diwakara, S. D.; McCandless, G. T.; Grinffiel, D. I.; Durand-Silva, A.; Thonhauser, T.; Smaldone, R. A. 2D-Covalent Organic Frameworks with Interlayer Hydrogen Bonding Oriented through Designed Nonplanarity. J. Am. Chem. Soc. 2020, 142, 12987-12994.

(2) Jiao, T.; Chen, L.; Yang, D.; Li, X.; Wu, G.; Zeng, P.; Zhou, A.; Yin, Q.; Pan, Y.; Wu, B.; Hong, X.; Kong, X.; Lynch, V. M.; Sessler, J. L.; Li, H. Trapping White Phosphorus within a Purely Organic Molecular Container Produced by Imine Condensation. Angew. Chem. Int. Ed. 2017, 56, 14545-14550.

(3) Pandey, P.; Katsoulidis, A. P.; Eryazici, I.; Wu, Y.; Kanatzidis, M. G.; Nguyen, S. T. ImineLinked Microporous Polymer Organic Frameworks. Chem. Mater. 2010, 22, 4974-4979.

(4) Bunck, D. N.; Dichtel, W. R. Bulk Synthesis of Exfoliated Two-Dimensional Polymers Using Hydrazone-Linked Covalent Organic Frameworks. J. Am. Chem. Soc. 2013, 135, 1495214955.

(5) Uribe-Romo, F. J.; Doonan, C. J.; Furukawa, H.; Oisaki, K.; Yaghi, O. M. Crystalline Covalent Organic Frameworks with Hydrazone Linkages. J. Am. Chem. Soc. 2011, 133, 1147811481.

(6) Luzuriaga, M. A.; Benjamin, C. E.; Gaertner, M. W.; Lee, H.; Herbert, F. C.; Mallick, S.; Gassensmith, J. J. ZIF-8 Degrades in Cell Media, Serum, and Some-but Not All-Common Laboratory Buffers. Supramol. Chem. 2019, 31, 485-490.

(7) Tutol, J. N.; Kam, H. C.; Dodani, S. C. Identification of mNeonGreen as a pH-Dependent, Turn-On Fluorescent Protein Sensor for Chloride. ChemBioChem 2019, 20, 1759-1765. 